\title{
Hiperpartitura: análise da rede de processos na criação de
}

\section{Khorwa-Myalwa, de Mikhail Malt}

\author{
Lucas Quinamo Furtado de Mendonça | Universidade Estadual de Campina \\ Danilo Rossetti | Universidade Federal de Mato Grosso
}

Jônatas Manzolli | Universidade Estadual de Campinas

\begin{abstract}
Resumo: Este artigo analisa o processo criativo de Khorwa-Myalwa (2016), para flauta baixo e eletrônica, de Mikhail Malt, criada sob o paradigma da composição assistida por computador (CAC). A nossa visão se ancora em três aspectos: a) as ideias sobre as tecnologias intelectuais e hipertexto do filósofo Pierre Lévy (2010), b) as teorias sobre criatividade computacional de Margaret Boden (2009; 2004) e c) as proposições teóricas a respeito dos modelos de Mikhail Malt (2015) e Ronald Giere (2004). Desenvolvemos então uma nova abordagem que considera o processo criativo como uma rede que entrelaça os vários agentes da CAC. Definimos a noção de hiperpartitura para representar essa rede de ferramentas computacionais, ambientes de programação, bancos de dados e representações que surgem durante a CAC. A hiperpartitura mostra-se uma valiosa ferramenta para a compreensão dos agenciamentos na CAC e é útil tanto ao analista quanto ao compositor interessado em compreender os seus processos.
\end{abstract}

Palavras-chave: hiperpartitura, composição assistida por computador, música mista, análise do processo criativo.

\begin{abstract}
This article analyses the creative process of Khorwa-Myalwa (2016), for bass flute and electronics, by Mikhail Malt, created under the computer-aided composition (CAC) paradigm. Our vision is anchored in three aspects: a) the ideas about intellectual technologies and hypertext by philosopher Pierre Lévy (2010), b) the theories about computer creativity by Margaret Boden (2009; 2004), and c) the theoretical propositions about models by Mikhail Malt (2015) and Ronald Giere (2004). We have then developed a new approach that considers the creative process as a network interacting with the various actors of CAC. We defined the notion of hyper-score to represent this network of computational tools, programming environments, databases and representations that arise during CAC. The hyper-score is a valuable tool for the comprehension of the agencies in CAC and is useful for both the analyst and the composer interested in understanding its processes.
\end{abstract}

Keywords: hyper-score, computer-aided composition, mixed music, creative process analysis. 


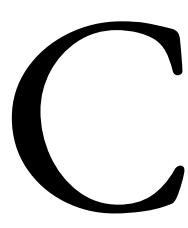

om o surgimento da microinformática na segunda metade do século passado, diversos compositores se debruçaram e se dedicaram aos processos composicionais assistidos por computador. Essas novas ferramentas certamente modificaram as práticas musicais dos compositores da época e delegaram ao século XXI novas formas de representar e pensar música - ter um computador é condição sine qua non para muitos na hora de compor. Esse campo de estudo e desenvolvimento criativo se apresenta na literatura a partir de diversos trabalhos como os de (HILLER; ISAACSON, 1959; BUXTON, 1977; LASKE, 1981; ASSAYAG et al., 1999; KIMIZUKA, 2019).

Contudo, ainda nos restam várias dúvidas a respeito do processo criativo: quais são essas ferramentas computacionais? Como são agenciadas entre si? Como elas se agenciam com a cognição do compositor? Tentando responder a essas perguntas, a partir de ponto de vista teórico, realizamos uma análise do processo de composição assistida por computador (doravante CAC) e das técnicas envolvidas na criação de Khorwa-Myalwa (2016) para flauta baixo e eletrônica em tempo diferido, do compositor Prof. Dr. Mikhail Malt, professor e pesquisador do time de Representação Musical (RepMus) do Institut de Recherche et Coordination Acoustique/Musique (IRCAM), Paris.

Essa obra foi composta para a flautista Profa. Dra. Cássia Carrascoza, professora de Flauta do Departamento de Música da Faculdade de Filosofia, Ciências e Letras de Ribeirão Preto da Universidade de São Paulo, para a gravação do CD “tempo transversal flauta expandida”, lançado pelo selo SESC. Mikhail Malt tomou como inspiração poética o texto tibetano Longchen Nyingtik Ngöndro, um livro sobre as práticas preliminares budistas, e a partir desse texto estruturou a forma e a criação de material sonoro para a obra. Em seu processo de composição, Malt fez uso de diversas ferramentas computacionais, tecendo uma verdadeira rede de técnicas, representações e significados com o auxílio do computador.

O referencial teórico deste artigo parte das ideias sobre as tecnologias intelectuais e hipertexto do filósofo e sociólogo francês Pierre Lévy (2010) para fundamentar nossa ideia de que no processo de CAC ocorre a criação do que chamamos de hiperpartitura. Esta é descrita e definida por uma rede complexa de interação entre aplicativos computacionais e arquivos digitais de áudio, no formato MIDI, SDIF, partituras PDF e imagem digitalizadas como gráficos enfim, várias 
ferramentas computacionais e arquivos digitais utilizados pelo compositor durante o processo criativo. Dado que cada um desses elementos da hiperpartitura têm função diferente e troca de informação de nível diferente com os outros, analisamos essa comunicação de processos computacionais e informação digital como o fluxo criativo do compositor. Ou seja, ao descrever a CAC na forma de hiperpartitura podemos representar, analisar e compreender melhor esse tipo de processo e fluxo criativo, principalmente no que diz respeito a como as diversas técnicas empregadas foram utilizadas e interligadas na prática pelo compositor.

Colocamos em perspectiva os conceitos de Lévy (2010) com as da pesquisadora da criatividade computacional Margaret Boden (BODEN, 2009; 2004), no que diz respeito aos processos cognitivos envolvidos na criatividade computacional. Também articulamos as ideias de modelos computacionais de Lévy com ideias do filósofo da ciência Ronald Giere (2004) e as ideias do próprio Mikhail Malt (2015), uma das importantes referências no estudo das representaçóes musicais e modelos computacionais para a CAC, bem como o desenvolvedor de diversas bibliotecas externas para OpenMusic (ASSAYAG et al., 1999) e Max/MSP (PUCKETTE, 2016).

Por fim, é importante citar que nossa análise do processo criativo só foi possível devido ao contato direto com Malt, que nos cedeu gentilmente todo o material de sua palestra ministrada na Unicamp, em 2018, a respeito do processo composicional da peça (slides que reproduzem diversos rascunhos), bem como a eletrônica em tempo diferido e o andaime, uma estrutura sonora eletroacústica construída para a criação da peça que foi, contudo, retirada na versão final. O contato com o compositor também nos permitiu duas entrevistas por email que serviram para tirar dúvidas e iluminar caminhos do processo composicional até então obscuros.

Dessa forma, a metodologia empregada nesta pesquisa tem um viés teórico que ancora informação etnográfica fornecida pelo compositor. O cruzamento das fontes genéticas da obra com o referencial teórico nos levou à construção da análise a qual nos propomos. É importante citar aqui os trabalhos de Nicolas Donin (2009) e François-Xavier Féron (2011) como referências para análise de processo criativo ancorado em informações etnográficas, contudo nosso trabalho se distancia dessas abordagens ao propor uma nova abordagem, fundamentada na compreensão da rede de técnicas, dados e processos cognitivos criada durante o processo criativo na CAC. 
Nas próximas seçôes apresentamos o referencial teórico a partir das noções de computador como tecnologia da inteligência, hipertexto e conhecimento por simulação (LÉVY, 2010); convergimos então para discussão sobre inteligência computacional (BODEN, 2004; 2009); discutimos a noção da mente humana organizada em redes de associação (LÉVY, 2010; BUSH, 1945) para então chegar à definição de Hiperpartitura na composição assistida por computador. No segundo aspecto teórico desenvolvido, apresentamos as ideias de Mikhail Malt (MALT, 2015) sobre modelos e representações. Por fim, seguindo a proposta metodológica de conciliar o referencial teórico com material etnográfico fornecido pelo compositor, realizamos a análise do processo criativo em Khorwa-Myalwa.

\section{Computer music e composição assistida.}

Os estudos da computer music tradicionalmente dividem a área em duas: a síntese de partitura (área geralmente associada à CAC) e a síntese sonora (envolvendo também a gravação e manipulação de amostras sonoras) (BUXTON, 1977, p. 59; LASKE, 1981, p. 36).

Para a primeira modalidade existem ainda duas abordagens: há tanto aquela cujo principal objetivo é a criação de programas ou algoritmos que deem conta de compor a peça sem maiores interferência do compositor a partir do momento de sua inicialização (a qual Buxton chama de composing programs, ou programas compositores em uma tradução livre), quanto aquela cujos compositores se utilizam do computador como um ferramenta de auxílio para gerar e modificar materiais musicais (a qual Buxton chama simplesmente de CAC) (BUXTON, 1977, p. 59).

Dentro da abordagem composing programs Buxton cita o trabalho de Hiller e Isaacson (1959) com a Illiac Suite e a composição de Atrées (1962) de Iannis Xenakis (BUXTON, 1977, p. 60-63). Para a CAC, Buxton cita particularmente o sistema SCORE, desenvolvido na Universidade de Stanford (SMITH, 1972; BUXTON, 1977, p. 63-64), mas podemos citar ainda o trabalho de Tristan Murail com a composição de Désintégrations (MURAIL, 2005).

Contudo, os exemplos supracitados e seus respectivos estudos publicados (HILLER, ISAACSON, 1959; XENAKIS, 1992; SMITH, 1972; MURAIL, 2005), apesar de descreverem e explicitarem os procedimentos matemáticos e/ou algorítmicos envolvidos na composição das peças, 
não dão conta de descrever a prática composicional em si. Isto é, não expõem a prática do compositor, como agenciou suas ferramentas, como transcreveu para a partitura o output do computador, se modificou ou não resultados do computador, se houve diversas simulações e consequentes modificações do algoritmo até a obtenção de um resultado agradável, etc.

Por outro lado, a divisão da computer music entre síntese de partitura e síntese sonora, embora útil em diversas situações e pragmática em muitos sentidos, não nos pareceu a maneira ideal de abordar nosso objeto em questão. O processo criativo por trás da peça de música mista KhorwaMyalwa, um processo criativo em que CAC e síntese sonora se confundem e se perpassam a todo instante, fez uso das mais variadas ferramentas, modelos e procedimentos para a criação tanto da parte da eletrônica quanto da flauta de modo que explicitar os modelos envolvidos poderia até explicar a criação de certos elementos musicais, mas não explicaria o processo de criação de maneira mais global.

Por esse motivo e em virtude da disponibilidade de trabalhar com rascunhos e materiais cedidos pelo compositor, desenvolvemos uma abordagem que se propóe a explicar a rede técnicas, processos cognitivos e seus agenciamentos, a qual chamamos de hiperpartitura e que representamos por meio de um grafo, como veremos na seção 2.4 do texto.

\section{O computador como tecnologia da inteligência}

Desde o surgimento da informática a humanidade viu-se no centro de inúmeras mudanças sociais, culturais e científicas. A partir dos anos 1970, novas interfaces computacionais permitiram ao grande público ter acesso e utilizar os mais recentes microcomputadores pessoais disponíveis no mercado, menores e mais acessíveis que os computadores do passado (LÉVY, 2010, p. 45-48). As recentes interfaces apresentavam-se ao usuário de maneira muito mais amigável e intuitiva: tela, mouse, teclado, ícones, cursor de mouse, menus, janelas, enfim, interfaces de uso sem as quais já não podemos mais conceber um computador (Ibid., p. 48-49).

Assim, tais interfaces permitiram que os computadores passassem a atuar no dia-a-dia das pessoas como tecnologias intelectuais (ou tecnologias da inteligência). Tecnologias essas que, além de possibilitarem novas práticas, "reorganizam, de uma forma ou de outra, a visão de mundo de 
seus usuários e modificam seus reflexos mentais” (Ibid., p. 54). Para Lévy, as tecnologias intelectuais possuem a capacidade de gerar "estilos de pensamento distintos" (Ibid., p. 78) e alterar nossa percepção e nossas representações sobre o tempo (Ibid., p. 87-88). O autor compara as mudanças no pensamento a partir do surgimento da informática com as mudanças desencadeadas pelo surgimento da escrita, para ele:

As tecnologias intelectuais misturaram-se à inteligência dos homens por duas vias. A escrita, por exemplo, serviu por um lado para sistematizar, para gradear ou enquadrar a palavra efêmera. Por outro lado, ela inclinou os letrados a ler o mundo como se fosse uma página, incitou-os a decodificar signos nos fenômenos, das tábuas de profecias dos magos da Caldeia à decifração do código genético, como se a vida, muito tempo antes dos Fenícios, tivesse inventado o alfabeto. (...), a escrita, ao intercalar um intervalo de tempo entre a emissão e a recepção da mensagem, instaura a comunicação diferida, com todos os riscos de mal-entendidos, de perdas e erros que isto implica. A escrita aposta no tempo. (Ibid., p. 71-88).

Por instaurar uma comunicação diferida, a escrita possibilitou que os discursos pudessem “ser separados das circunstâncias particulares em que foram produzidos” (Ibid., p. 88), da mesma forma que também possibilitou o surgimento de "saberes cujos autores geralmente pretenderam que fossem independentes das situações singulares em que foram elaborados e utilizados: as teorias” (Ibid., p. 90).

Num processo similar, é a partir do surgimento da informática que a linearidade dos textos escritos cede lugar à organização da informação em novas estruturas em rede, o hipertexto (Ibid., p. 58), que invariavelmente alterou as representações com que compreendemos o mundo.

\subsection{Hipertexto}

Segundo Lévy, a noção de hipertexto começa a surgir, ainda sem este nome, em 1945, a partir do texto “As We May Think”, do engenheiro Vannevar Bush. Apesar da informática incipiente da época, Bush esboçou em seu texto as noções que viriam a fundamentar o conceito de hipertexto (LÉVY, 2010, p. 28-29; BUSH, 1945).

Ele problematizou a "artificialidade dos sistemas de indexação", já que aquele que procura uma determinada informação em um catálogo precisa percorrer uma lista alfabética ou numérica 
onde "a informação é achada (quando é) rastreando de subclasse em subclasse" (BUSH, 1945, p. 121). A partir disso, concebeu um artefato, o qual chamou de memex, capaz de armazenar uma quantidade enorme de informação - livros, jornais, periódicos, imagens, gravaçốes - e empreender uma busca rápida e flexível, através de um sistema de indexação associativa, "cuja ideia básica é a disposição de que qualquer item possa ser usado à vontade para selecionar imediatamente e automaticamente outro (Ibid., p. 123).

É justamente essa capacidade de ligar itens distintos que gera a rede de conexóes transversais que configura o hipertexto. Nas palavras de Lévy:

Tecnicamente, um hipertexto é um conjunto de nós ligados por conexões. Os nós podem ser palavras, páginas, imagens, gráficos ou partes de gráficos, sequências sonoras, documentos complexos que podem eles mesmos ser hipertextos. Os itens de informação não são ligados linearmente, como uma corda com nós, mas cada um deles, ou a maioria, estende suas conexões em estrela, de modo reticular. Navegar em um hipertexto significa portanto desenhar um percurso em uma rede que pode ser tão complicada quanto possível. Porque cada nó pode, por sua vez, conter uma rede inteira. (LÉVY, 2010, p. 33)

O autor ainda elenca seis princípios que caracterizam o hipertexto: (1) a metamorfose, de modo que "a rede hipertextual está em constante construção e renegociação"; (2) a heterogeneidade, que define os nós como podendo ser "imagens, sons, palavras, diversas sensaçóes, modelos, etc" e as conexôes podem ser "lógicas, afetivas, etc"; (3) a multiplicidade e encaixe de escalas, assim, "o hipertexto se organiza em um modo 'fractal', ou seja, qualquer nó ou conexão (...) pode revelar-se como sendo composto por toda uma rede, e assim por diante"; (4) a exterioridade, pelo qual "seu crescimento e sua diminuição, sua composição e recomposição permanentemente dependem de um exterior indeterminado"; (5) a topologia, de maneira que "nos hipertextos tudo funciona por proximidade, por vizinhança” e, consequentemente, "tudo que se desloca deve utilizar-se da rede hipertextual tal como ela se encontra, ou então será obrigado a modificá-la”; e (6) a mobilidade de centros, que define a rede como não possuindo centro, "ou melhor, possui permanentemente diversos centros” (LÉVY, 2010, p. 25-26).

Ainda, os computadores efetivamente empregam o hipertexto em sua estrutura: o computador é uma rede de interfaces, organizadas por camadas de programas que se intercomunicam (Ibid., p. 58). Como resultado dessa estrutura, o computador passa a empregar um 
tempo diferente do da escrita, onde ocorre “a condensação no presente, na operação em andamento” ou, em outras palavras, a informática opera em tempo real (Ibid., p. 116). A consequência disso é que o computador é capaz de gerar simulações de modelos digitais:

O saber informatizado afasta-se tanto da memória (este saber "de cor"), ou ainda a memória, ao informatizar-se, é objetivada a tal ponto que a verdade pode deixar de ser uma questão fundamental, em proveito da operacionalidade e velocidade. (...) As teorias, com suas normas de verdade e com a atividade crítica que as acompanha, cedem terreno aos modelos (LÉVY, 2010, p. 120-121).

(...)Entre outros, ficou claro para nós que a cultura informático-mediática é portadora de um certo tipo de temporalidade social: o "tempo real", e de um "conhecimento por simulação", não inventariado antes da chegada dos computadores (LÉVY, 2010, p. 135).

\subsection{Conhecimento por simulação}

A simulação não é uma possibilidade restrita à informática: a mente humana é capaz de realizar simulações através da imaginação de modelos mentais que dão conta de "antecipar o resultado de nossas intervenções e usar a experiência acumulada” (LÉVY, 2010, p. 70). Se a escrita, por um lado, possibilitou a criação de modelos científicos gerais, chamados teorias (GIERE, 2004), mas que permanecem inertes, estáticos; a informática, por outro, possibilitou que os modelos sejam “continuamente corrigidos e aperfeiçoados ao longo das simulações” (LÉVY, 2010, p. 121). Assim, "um modelo digital não é lido ou interpretado como um texto clássico, ele geralmente é explorado de forma interativa” e, portanto, é “essencialmente plástico, dinâmico, dotado de uma certa autonomia de ação e reação.” (Ibid., p. 122).

Dessa forma, o surgimento da informática produziu também uma nova categoria de conhecimento, um conhecimento por simulação, menos abstrato e mais operacional que o conhecimento teórico da escrita (Ibid., p. 122). A capacidade de que o usuário do modelo manipule os parâmetros e simule diversas circunstâncias possíveis confere a ele: "uma espécie de intuição sobre as relações de causa e efeito presentes no modelo. Ele adquire um conhecimento por simulação do sistema modelado, que não se assemelha nem a um conhecimento teórico, nem a uma experiência prática, nem ao acúmulo da tradição oral.” (Ibid., p. 123-124). 
Como consequência, a cognição humana - isto é, "o resultado de redes complexas onde interagem um grande número de atores humanos, biológicos e técnicos” (Ibid., p. 137) territorializa o conhecimento por simulação não só pelo uso prático das simulações e modelos, mas também pela transformação do “meio no qual se propagam as representações” (Ibid., p. 140).

As técnicas agem, portanto, diretamente sobre a ecologia cognitiva, na medida em que transformam a configuração da rede metassocial, em que cimentam novos agenciamentos entre grupos humanos e multiplicidades naturais tais como ventos, flores, minerais, elétrons, animais, plantas ou macromoléculas. Mas elas agem, também, sobre as ecologias cognitivas de forma indireta, já que (...) são potentes fontes de metáforas e analogias. (Ibid., p. 146-147)

O computador não é apenas uma extensão da memória humana, ele é a própria extensão da faculdade de imaginar, realizando as simulações mentais humanas de maneira muito mais eficaz e veloz. É possível, portanto, falar em uma “imaginação auxiliada por computador” (Ibid., p. 125), ou ainda, em uma criatividade computacional.

\subsection{Criatividade computacional}

Para a pesquisadora da criatividade computacional, Margaret Boden:

Criatividade pode ser definida como a habilidade de gerar ideias novas e valiosas. Valiosas, aqui, tem muitos significados: interessante, útil, bonito, simples, rico, complexo, e por aí vai. Ideias significam também muitas coisas: não apenas ideias em si (conceitos, teorias, interpretações, histórias), mas também artefatos como imagens gráficas, esculturas, casas e motores a jato. Modelos computacionais foram criados para gerar ideias em todas essas áreas e mais. (BODEN, 2009, p. 24, tradução nossa ${ }^{1}$ ).

Ainda, a criatividade pode ser compreendida a partir da maneira com que opera em relação a um determinado espaço conceitual, ou "estilos estruturados de pensamento" (BODEN, 2004, p. 3). Pode ser de caráter combinatório, de maneira que ideias comuns e familiares são reorganizadas

\footnotetext{
${ }^{1}$ Creativity can be defined as the ability to generate novel, and valuable, ideas. Valuable, here, has many meanings: interesting, useful, beautiful, simple, richly complex, and so on. Ideas covers many meanings too: not only ideas as such (concepts, theories, interpretations, stories), but also artifacts such as graphic images, sculptures, houses, and jet engines. Computer models have been designed to generate ideas in all these areas and more (Boden 2009).
} 
em uma nova ideia. Dentro desta categoria encontram-se colagens, analogias, imagens poéticas e citaçôes musicais (BODEN, 2004, p. 2-3).

A criatividade também pode ser de caráter exploratório, em que um determinado espaço conceitual é explorado dentro de seus limites. Se um compositor compõe sua música para funcionar dentro do sistema tonal, por exemplo, está realizando uma exploração (a composição) de um espaço conceitual (estruturas harmônicas, melódicas e formais do tonalismo). Explorar um espaço conceitual nos abre para muitas possibilidades, mas o “estilo” está dado, não há nada fundamentalmente novo em relação a esta maneira de pensar (BODEN, 2004, p. 3-4).

Em determinadas situações, contudo, o indivíduo precisa não apenas explorar um dado espaço conceitual, mas expandir, ou, transformar o espaço em que está inserido. Transformação do espaço conceitual é, portanto, outra maneira com que a criatividade opera (BODEN, 2004, p. 45). Picasso pode um dia ter se deparado com os limites do desenho realista e transformou a maneira como concebia figuras e imagens, desenvolvendo sua estética cubista.

Para que um computador explore um determinado espaço conceitual - por exemplo, a escrita de uma sonata clássica - é necessário que o programador inscreva no programa as regras que regem tal espaço conceitual (BODEN, 2004, p. 158-159): a representação das notas musicais, das dinâmicas, da instrumentação, as regras e procedimentos harmônicos do tonalismo, as regras da forma sonata, etc. Ao fazê-lo, o programador estará não apenas criando um modelo computacional para a composição de uma sonata, mas estará ele mesmo descobrindo as regras que regem a sonata e as testando através de simulações.

Se o programador estiver, contudo, interessado que o computador não apenas explore um espaço conceitual, mas que ele também o transforme, ele terá outro problema em mãos. Ele não irá meramente inscrever regras de um espaço conceitual, mas irá inscrever no programa a heurística que rege as mudanças de tal espaço conceitual (BODEN, 2004, p. 165).

Por último, o computador pode ainda realizar procedimentos combinatórios, embora esta seja para Boden o tipo de criatividade mais difícil de se reproduzir: a criatividade combinatória requer daquele que a produz uma grande rede de associaçóes e de significados entre ideias distintas (BODEN, 2009, p. 25). A mente humana, organizada em redes de associação (LÉVY, 2010; BUSH, 1945), é capaz de rapidamente combinar duas ideias com base em um dado contexto, mas, para que 
o computador teça tais relações e representações entre ideias distintas, é necessário um enorme banco de dados e esforço de programação (BODEN, 2009, p. 25-26).

Diferentemente de Boden, que foca seus estudos na inteligência artificial criativa, nosso interesse aqui é analisar como que o uso do computador na CAC apresenta efetivamente uma transformação do espaço conceitual do compositor ao engendrar novas maneiras de se representar e criar música. Assim, o compositor que se debruçar sobre a CAC também precisará inscrever no programa as regras de seu espaço conceitual.

Entretanto, o compositor não está confinado a um programa cuja função é apenas gerar a sua peça do começo ao fim, mas abre-se a ele a oportunidade de utilizar diversas ferramentas computacionais. Porém, não há somente uma partitura sobre a qual o compositor escreve suas ideias e rabisca seus rascunhos: surge uma rede de ferramentas, uma hiperpartitura que se estende sobre a cognição do compositor ao permitir novos agenciamentos entre materiais musicais, afetos, técnicas, informações, etc.; e estabelece novas representações para pensar sua prática composicional.

\subsection{Hiperpartitura na composição assistida por computador}

A partir do conceito de hipertexto apresentado por Lévy, propomos então a ideia de hiperpartitura, que nos servirá aqui para analisar o processo de CAC da peça Khorwa-Myalwa, para flauta baixo e eletrônica em tempo diferido, do compositor Mikhail Malt.

A hiperpartitura emprega uma estrutura hipertextual, onde as relações entre os nós são tecidas pelo compositor para criar uma rede de associaçôes entre materiais, processos e operaçóes musicais. Os nós são desde os típicos programas utilizados na CAC até bancos de dados: DAWs, ambientes digitais para síntese e controle de áudio como Max/MSP e Pure Data, ambientes para manipulação de materiais musicais como o OpenMusic, plug-ins de efeitos de áudio, descritores de áudio, programas para manipulação e processamento como Spear ou Audiosculpt, bancos de amostras de áudio online ou offline, bancos de arquivos MIDI, SDIF, imagens, partituras em PDF e seus editores, leitores de mídia e até mesmo editores de vídeo. Em suma, todas as ferramentas e interfaces utilizadas durante o processo de CAC. 
Estes nós podem ser, eles mesmos, outras hiperpartituras, como é o caso de ambientes de programação como Max/MSP, Pure Data, OpenMusic, etc. Nesses ambientes encontram-se ferramentas distintas, organizadas em rede, para a realização das mais diversas funções e operaçôes. Pode-se tecer ligações com outras aplicações externas, como é o caso do uso de plug-ins, ou expandir suas funcionalidades através de bibliotecas. Também é necessário que a hiperpartitura seja entendida para além da mera criação de representações gráficas em partitura, ela deve ser pensada como a própria possibilidade de que o compositor crie a música em tempo real, através do uso de síntese, controle e manipulação de áudio.

A estrutura hipertextual permite à hiperpartitura ser articulada de diversas formas. Pode-se criar modelos complexos que dão conta de produzir a música a partir de uma única aplicação. Também pode-se articular diversos outros modelos menores em programas distintos, que dão conta de tarefas isoladas e são unidas pelo compositor em uma rede de modelos-rascunhos para serem, finalmente, sintetizadas na obra final. As diversas possibilidades de agenciamentos da hiperpartitura resultam em redes particulares a cada compositor e a cada nova criação.

De uma forma ou de outra, o compositor interessado na CAC precisará detalhar modelos que deem conta de operações e procedimentos composicionais específicos: modelos para geração de harmonia, modelos rítmicos, curvas de intensidade para controlar parâmetros eletroacústicos. A criação transforma-se em um ato de representar.

Por conta de sua estrutura em rede, decidimos representar a hiperpartitura observada em nosso trabalho através do uso de um grafo como uma forma de representar e dar sentido à enorme quantidade de informações que possuíamos sobre o processo criativo. Sua aplicação será averiguada mais adiante no texto. De fato, um grafo é uma representação matemática de uma rede (BARABÁSI, 2014, p. 6) e, portanto, é uma ótima maneira de se representar qualquer hiperpartitura.

Um grafo pode ser entendido como um “catálogo dos componentes de um sistema, chamados nós ou vértices, e as interações entre eles, chamadas ligaçôes ou arestas”, sendo que as arestas podem ser direcionais ou não direcionais (BARABÁSI, 2014, p. 5). A direcionalidade das arestas do grafo indica o caminho por onde a informação passa (seja ela arquivos de áudio, arquivos MIDI, representações numéricas, etc.). Também consideramos, para a criação do nosso grafo, a 
existência de bubs, ou "nós altamente conectados" (ibid., p. 27). Estes hubs nos indicaram pólos em que o processo criativo de Khorwa-Myalwa se concentrou.

Vale mencionar aqui o trabalho de Maniatakos et al. (2015), que se utilizou da teoria dos grafos para criar uma arquitetura de reinjeção de estilo (style reinjection) em sistemas de improvisação assistida por computador. Os autores representaram os estilos musicais por meio de um conjunto de grafos e definiram diversas operaçóes e processamentos com esse conjunto, de forma a ser possível agenciar grandes quantidades de informação em tempo real por parte do computador, ao mesmo tempo que é fornecido ao intérprete do computador representaçóes musicais de alto nível (MANIATAKOS et al., 2015, p. 5). Essa arquitetura estava, à época, sendo implementada em um software em desenvolvimento chamado GrAIPE (Graph Assisted Interactive Performance) (Ibid., p. 8).

\section{Modelos e representações}

Pode-se pensar o modelo como algo que nos permite representar a realidade e, consequentemente, discuti-la, analisá-la, teorizá-la: “o estudo dos modelos, das formalizações e de representações tem como objetivo principal a construção de suportes para pensar, para conhecer ou para comentar o fenômeno estudado" (MALT, 2015, p. 32). O modelo é, portanto, uma tecnologia intelectual.

Embora possuam diversas formas, usos e implicações, os modelos reportam-se a algum fenômeno ou objeto ideal, podendo também ser ele mesmo um objeto físico ou uma ideia. $\mathrm{O}$ modelo não é de fato o objeto ou fenômeno, mas se relaciona ao objeto original e o reporta àquele que o apreende através de algum processo de representação: o modelo é a representação do objeto/fenômeno. O processo de representação é descrito por Malt (2015, p. 40-41) da seguinte maneira:

A - É um objeto representante, ou representativo. A é uma representação de B.

B - É o objeto, fenômeno representado ou o domínio (espaço de parâmetros) que devem ser representados.

C - É um agente cognitivo exterior construtor da representação.

D - É um agente cognitivo exterior destinatário, interpretante da representação.

$\mathbf{R}$ - É uma relação objetiva apreendida por $\mathrm{C}$, conectando $\mathrm{A}$ à $\mathrm{B}$. 
Malt também afirma que “o ato de representação, representar, é, portanto, também um ato de criação, de concepção de um ‘substituto' a uma entidade inteligente ou sensível” (MALT, 2015, p. 38). O filósofo da ciência Ronald Giere observa ainda que não é o modelo que se representa ao observador, mas é o observador quem realiza a representação (2004, p. 746-747).

Para Giere a intencionalidade das representações é um fator fundamental e é esta que fornece o sentido da representação. Para ele o processo de representação pode ser descrito da seguinte maneira: $\mathbf{S}$ usa $\mathbf{X}$ para representar $\mathbf{W}$ pelo motivo $\mathbf{P}$ (2004, p. 743). Podemos traduzir a proposição lógica sobre a representação de Giere para o modelo de representação proposto por Malt da seguinte maneira:

$O$ agente exterior $\boldsymbol{C}$ utiliza $\boldsymbol{A}$ para representar $\boldsymbol{B}$ a um destinatário $\boldsymbol{D}$, através de uma relação $\boldsymbol{R}$ com o propósito $\boldsymbol{P}$.

Por outro lado, essa relação $\mathbf{R}$ implica necessariamente que aquele que se dirige ao modelo (seja ele $\mathbf{C}$ ou $\mathbf{D}$ ) possua as ferramentas necessárias para decodificar o significado da representação. Esta subjetividade contingente à representação é um problema que precisa ser resolvido, uma boa representação é aquela que dá conta de estabelecer essa relação $\mathbf{R}$ de maneira mais objetiva possível. É claro, toda representação só pode ser considerada objetiva dentro de um contexto, cultura ou sistema, contudo a partir de um dado referencial podemos estabelecer entre objeto representado e representante relações de entendimento comum para que a representação obtenha seu sentido. Lévy também ressalta o caráter contextual e relativo dos modelos:

O conhecimento por simulação, por sinal, só tem validade de dentro de um quadro epistemológico relativista. Se não, o criador de modelos poderia se deixar levar pela crença de que seu modelo é "verdadeiro", que ele "representa" no sentido forte a "realidade", esquecendo que todo modelo é construído para determinado uso de determinado sujeito em um momento dado. (LÉVY, 2010, p. 126)

Essas representações funcionam através de relaçôes analógicas, isto é, "um grupo de relaçôes estabelecidas pela imaginação entre duas coisas ou dois fenômenos, físicos ou abstratos. Essas 
relações podem ser relações de forma, estrutura (proporção), de natureza funcional ou convencional” (MALT, 2015, p. 42).

Estas relaçôes são de duas categorias distintas e definem o tipo de modelo proposto: as relações qualitativas (a qual Malt chamou de metafóricas em seu trabalho) e as relaçóes quantitativas (chamadas apenas de analógicas) (MALT, 2015, p. 44). Em seu estudo, considera que a "associação de proposições articuladas em linguagem natural manipulando os conceitos ou representações qualitativas abstratas” leva a criação de modelos não-formais (2015, p. 33). Os modelos formais, por outro lado, se baseiam nas "relações lógicas entre proposições expressas em uma linguagem formal, manipulando as representaçóes calculáveis” (2015, p. 34). Por se utilizarem das relações quantitativas (numéricas, relações estas que podem ser computadas e processadas) os modelos formais são mais aptos a serem reproduzidos e inscritos em espaço computacional.

No caso da modelagem musical, as representações utilizadas na construção do modelo representam materiais musicais (como alturas, ritmos, timbres, técnicas) e processos (como a transformação de um dado material ao longo do tempo da música). Portanto, entende-se que qualquer modelo para uma criação musical não pode ser descrito sem o auxílio de representaçóes que detalham e explicitam tais materiais e processos da maneira mais adequada ao compositor, ou seja, representações que cumpram o propósito do compositor. Se um compositor prefere, por exemplo, representar as alturas de seu novo modelo composicional no domínio da frequência ao invés do domínio das notas, essa maneira de pensar implica numa abordagem musical radicalmente diferente, digamos, de uma fuga barroca. Assim, as diferentes representações musicais utilizadas na CAC integram a ecologia cognitiva do compositor, possibilitando formas de conceber a música que não seriam possíveis antes dos computadores.

A seguir, descreveremos os caminhos pelo qual o processo criativo passou e, por fim, apresentaremos nossa representação da hiperpartitura criada por Malt para a composição da peça. Por fim, teceremos a partir do grafo da hiperpartitura algumas conclusóes e discutiremos como os componentes da hiperpartitura se agenciaram durante o processo de composição assistida em Khorwa-Myalwa. 


\section{Análise do processo criativo em Khorwa-Myalwa}

\subsection{Modelo literário em Khorwa-Myalwa}

A criação de Khorwa-Myalwa teve como ponto de partida o texto tibetano Longchen Nyingtik Ngöndro, em especial os trechos Karma: causa e efeito e O sofrimento de Samsara (ambos incluídos na primeira parte "As preliminares comuns ou externas" do texto). Foi com base nos trechos do texto que o compositor estruturou a forma da peça.

De Karma: causa e efeito foi feita a introdução da peça e de Sofrimento de Samsara, especificamente dos trechos 18 infernos e Renúncia, foi construído o restante da peça e a coda (MALT, 2018). O modelo literário (e, portanto, não-formal) de Khorwa-Myalwa serviu para organizar conceitualmente a forma musical, suas estruturas internas e até mesmo materiais musicais.

A peça está dividida em sete seçốes maiores (subdivididas num total de 25 subseçôes menores) que consistem em um total de 8'44": Introduction (Karma), Enfers Chauds (Infernos Quentes), Enfers Froids (Infernos Frios), Enfers Avoisinants (Infernos Vizinhos), La colline au Salmali de fer (A Colina Salmali de Ferro), Enfers Éphémères (Infernos Efêmeros) e por fim Chant (triste) de renoncement - Coda (Canto triste de renúncia - coda) (MALT, 2016; MALT, 2018). Todos esses trechos da peça se relacionam poeticamente aos trechos do poema do Longchen Nyingtik Ngöndro e foram pensados seguindo determinadas proporções elaboradas pelo compositor, de modo que, ao todo, a introdução e as cinco seções seguintes possuem um total de 8' (MALT, 2016; MALT, 2018, p.30 - Figura 1). A coda (ou Chant (triste) de renoncement) é a única seção da peça que não teve sua duração predeterminada pelo compositor (MALT, 2018, p.30; MALT, 2020) (Figura 2). 


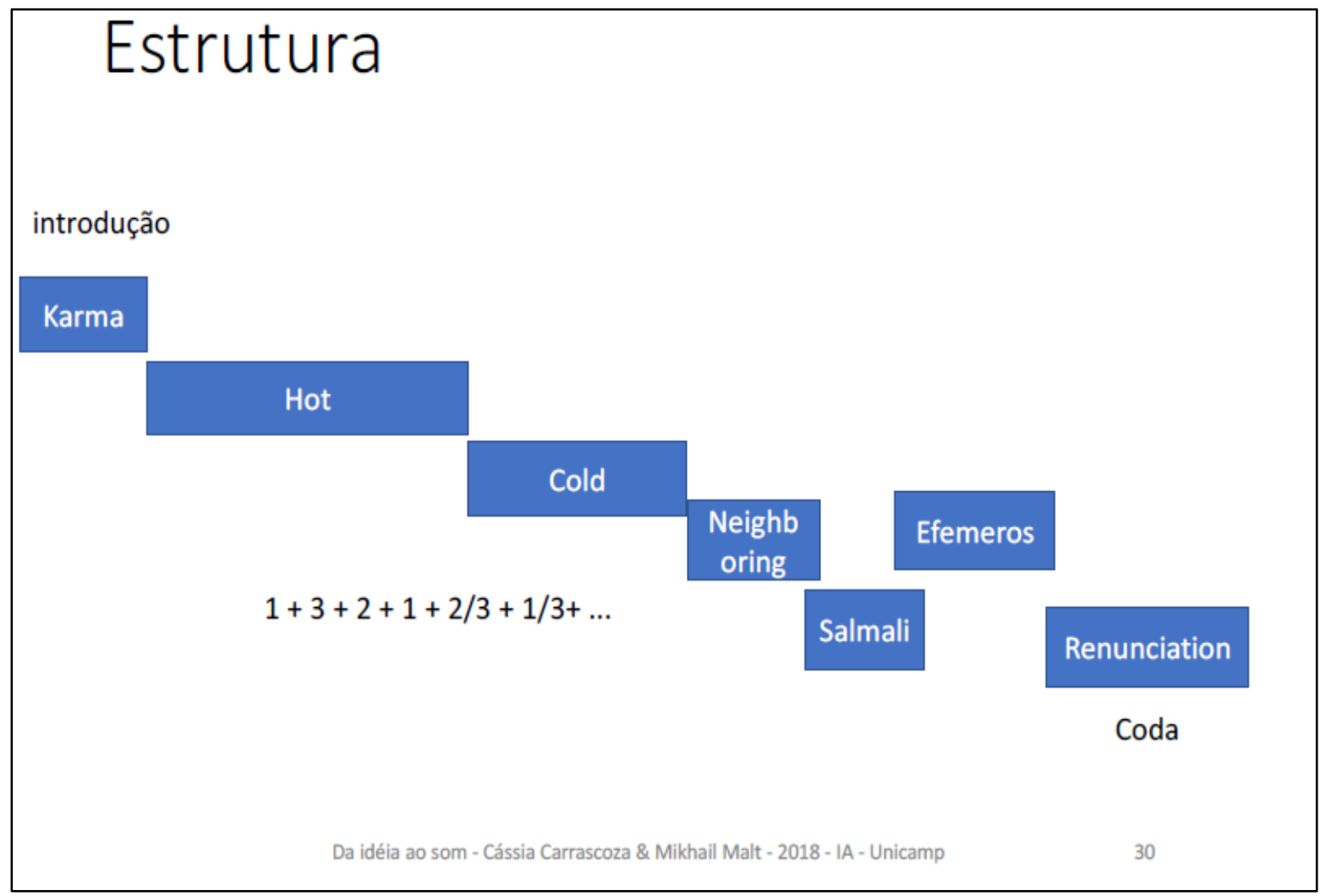

\section{Fonte: $\operatorname{MALT}(2018$, p. 30)}

Apesar das proporçôes descritas por Malt em seus rascunhos serem exatas, os trechos da peça não obedecem sempre com exatidão à elas, desviando ligeiramente em alguns casos, como a seção Enfers Chauds, que na proporção planejada teria duração equivalente a 3' e na proporção real da peça possui 3'05”, ou desviando drasticamente como no caso da seção La colline au Salmali de fer, que possui apenas metade do tempo inicialmente planejado (Tabela 1).

Nas duas tabelas a seguir estão apresentadas as seções, subseções, suas durações, a proporção planejada e a proporção real (isto é, a proporção final escrita e efetivamente realizada na peça): 
TABELA 1 - Seções da peça, com suas proporções planejadas, realizadas e a duração.

\begin{tabular}{lr|rr} 
Seção & Proporção planejada & Proporção real & \multicolumn{2}{|c}{ Duração } \\
Introduction & 1 & 1 & $01: 00$ \\
Enfers chauds & 3 & 3,05 & $03: 03$ \\
Enfers Froids & 2 & 1,9 & $01: 54$ \\
Enfers Avoisinants & 1 & 1,233333333 & $01: 14$ \\
La coline au Salmali de fer & 0,666666667 & 0,366666667 & $00: 22$ \\
Enfers Ephémeres & 0,333333333 & 0,2 & $00: 12$ \\
CODA & Não definida & Não definida & $00: 59$ \\
Total: & 8+coda & & $08: 44$ \\
\hline
\end{tabular}

Fonte: Autores

TABELA 2 - Subseções e seus respectivos tempos de início e duração.

\begin{tabular}{|c|c|c|}
\hline Subseção & Início & Duração da subseção \\
\hline Introduction (Karma) - 1 & $00: 00$ & $00: 24$ \\
\hline Introduction (Karma) - 2 & $00: 24$ & $00: 36$ \\
\hline Ressurections & $01: 00$ & $00: 19$ \\
\hline Lignes Noires & $01: 19$ & $00: 21$ \\
\hline Réunion et Eclatement & $01: 40$ & $00: 27$ \\
\hline Pleurs et Hurlements & $02: 07$ & $00: 23$ \\
\hline Grands Pleurs et Hurlements & $02: 30$ & $00: 22$ \\
\hline Brûlant & $02: 52$ & $00: 21$ \\
\hline Extrêment Brûlant & $03: 13$ & $00: 27$ \\
\hline Tourments Insurpassables & $03: 40$ & $00: 23$ \\
\hline Cloques & $04: 03$ & $00: 12$ \\
\hline Cloques Percées & $04: 15$ & $00: 12$ \\
\hline Claquement de Dents & $04: 27$ & $00: 13$ \\
\hline Lamentations & $04: 40$ & $00: 12$ \\
\hline Grognements & $04: 52$ & $00: 14$ \\
\hline Crevasses I (paréil aux Nénuphars) & 05:06 & $00: 27$ \\
\hline Crevasses II & $05: 33$ & 00:07 \\
\hline Crevasses III (paréil aux grand lotus) & $05: 40$ & $00: 17$ \\
\hline Fossée aux braises & 05:57 & $00: 28$ \\
\hline Marais aux cadavres putrescents & $06: 25$ & $00: 14$ \\
\hline Plaine hérissée de lames & $06: 39$ & $00: 14$ \\
\hline Forêt & $06: 53$ & $00: 18$ \\
\hline La coline au Salmali de fer & 07:11 & $00: 22$ \\
\hline Enfers Ephémeres & $07: 33$ & $00: 12$ \\
\hline Chant (triste) de renoncement & $07: 45$ & $00: 59$ \\
\hline Término & $08: 44$ & \\
\hline
\end{tabular}




\subsection{Curvas de intensidade dramática e o andaime}

Além de estabelecer durações para cada seção da peça, o compositor criou o que chamou de curvas de intensidade dramática (MALT, 2020b), ou seja, linhas que foram inicialmente concebidas para representar a evolução dos parâmetros e processos ao longo das seçóes da peça. Em troca de e-mails, o compositor nos revelou que estas curvas foram utilizadas para a composição geral da peça, tanto para a escrita instrumental da flauta, quanto para a composição de elementos presentes na parte eletrônica. Com as curvas desenhadas pôde-se visualizar a evolução dos parâmetros musicais dentro da forma estabelecida, para em seguida redesenhá-las dentro dos programas utilizados durante o processo de CAC de Khorwa-Myalwa.

As curvas foram inicialmente criadas em papel milimetrado (Figura 2), onde Malt representou a forma da peça (em que o eixo X representa a passagem do tempo, da esquerda para a direita) e os parâmetros musicais (em que o eixo $\mathrm{Y}$ representa os mínimos e máximos dos parâmetros) de acordo com as medidas do papel. Dessa forma, o compositor esboçou uma forma geral para a peça com suas devidas proporções gráficas e, ao representá-la desta forma, pôde, de certa forma, simular e prever mentalmente os resultados.

Quando as curvas de intensidade dramática foram passadas do espaço da escrita para o espaço informatizado, Malt atribuiu valores específicos para os valores máximo e mínimo dos parâmetros descritos por ele pelas diversas curvas criadas em papel.

Dentro do Max/MSP, Malt utilizou o objeto function para representar as curvas de intensidade dramática (Figuras 3), estas functions serviram para controlar parâmetros da síntese granular realizada pelo objeto munger , objeto presente na biblioteca PerColate, para criar o que Malt chamou de andaime (MALT, 2020a).

O andaime nada mais é do que um arquivo de áudio que serviu como base para a criação da parte da eletrônica e como fonte de material harmônico para a escrita da flauta. Ele contém as dinâmicas e evoluçóes preestabelecidas pelas curvas, mas foi, em sua maioria, retirado da eletrônica no final do processo - da mesma forma com que os andaimes são retirados após o término de uma construção (MALT, 2018; MALT, 2020a). 
Para sua criação, Malt partiu da gravação de uma narração dos trechos do texto que serviram de inspiração para a composição da peça. Essa gravação, contudo, foi expandida através da ferramenta de time-stretching ${ }^{2}$ do Audiosculpt, partindo de 1'22” para exatos 8' (MALT, 2020a). $\mathrm{O}$ arquivo resultante foi então processado pelo objeto munger citado acima, resultando num arquivo de 8’38” - o andaime. Questionado se as proporções estabelecidas por Malt para cada seção da peça eram análogas às durações dos trechos na gravação, o compositor afirmou que não conseguiu coincidir os trechos do texto com as proporções da peça (MALT, 2020a).

FIGURA 2 - Curvas de intensidade de parâmetros da síntese granular em esboço, a ser implementadas em Max/MSP (marcação em vermelho do original).

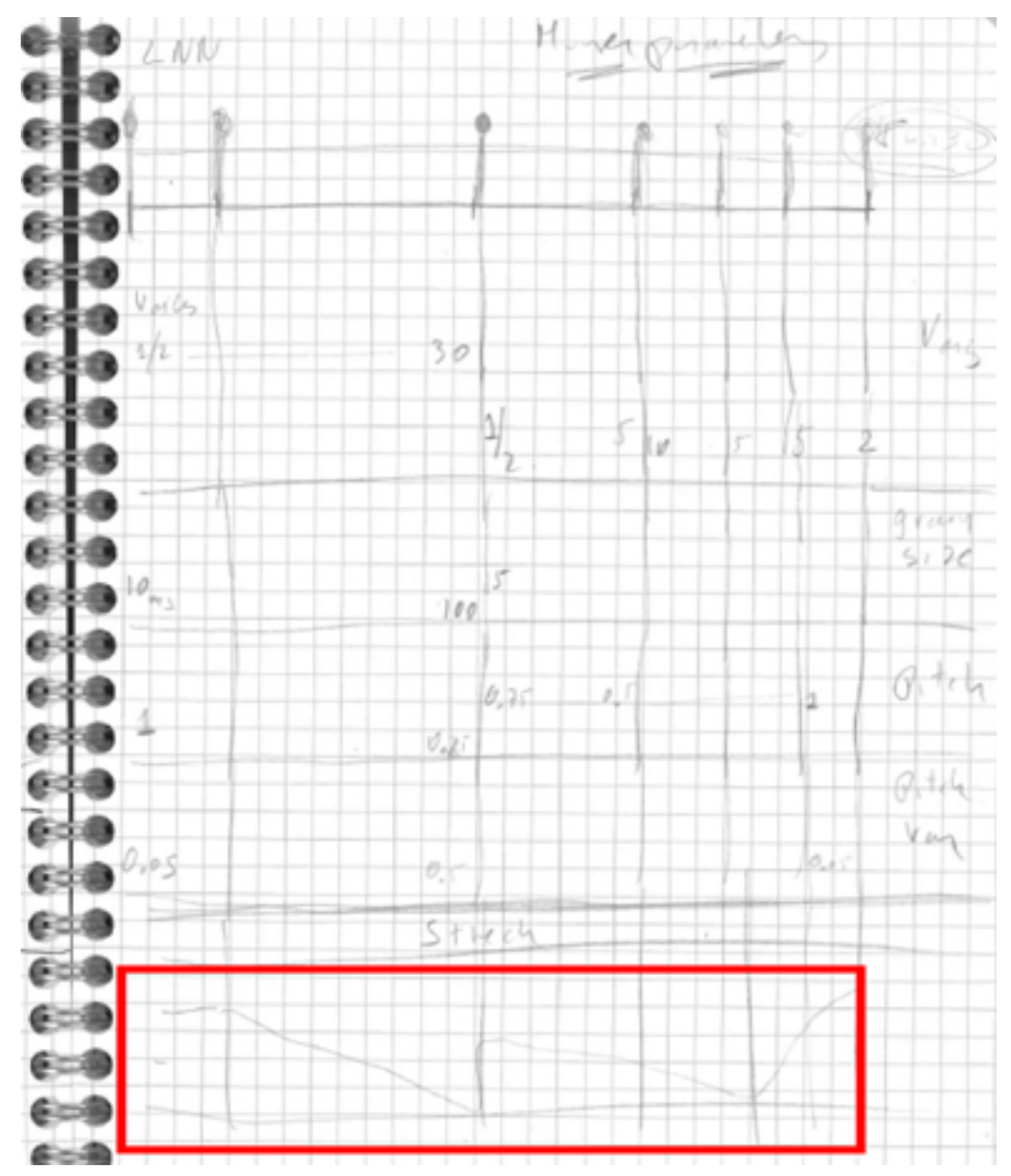

Fonte: MALT (2018, p. 51)

\footnotetext{
${ }^{2}$ A ferramenta de time-scale modification (modificação de escala temporal, em tradução livre), comumente chamado de time stretch (expansão do tempo, em tradução livre), é utilizada para diminuir ou aumentar a duração de um áudio sem que sua altura seja modificada. (DRIEDGER, MÜLLER, 2016).
} 
FIGURA 3 - Curvas de intensidade dramática dentro do patch de síntese granular em Max/MSP (marcação em vermelho do original).

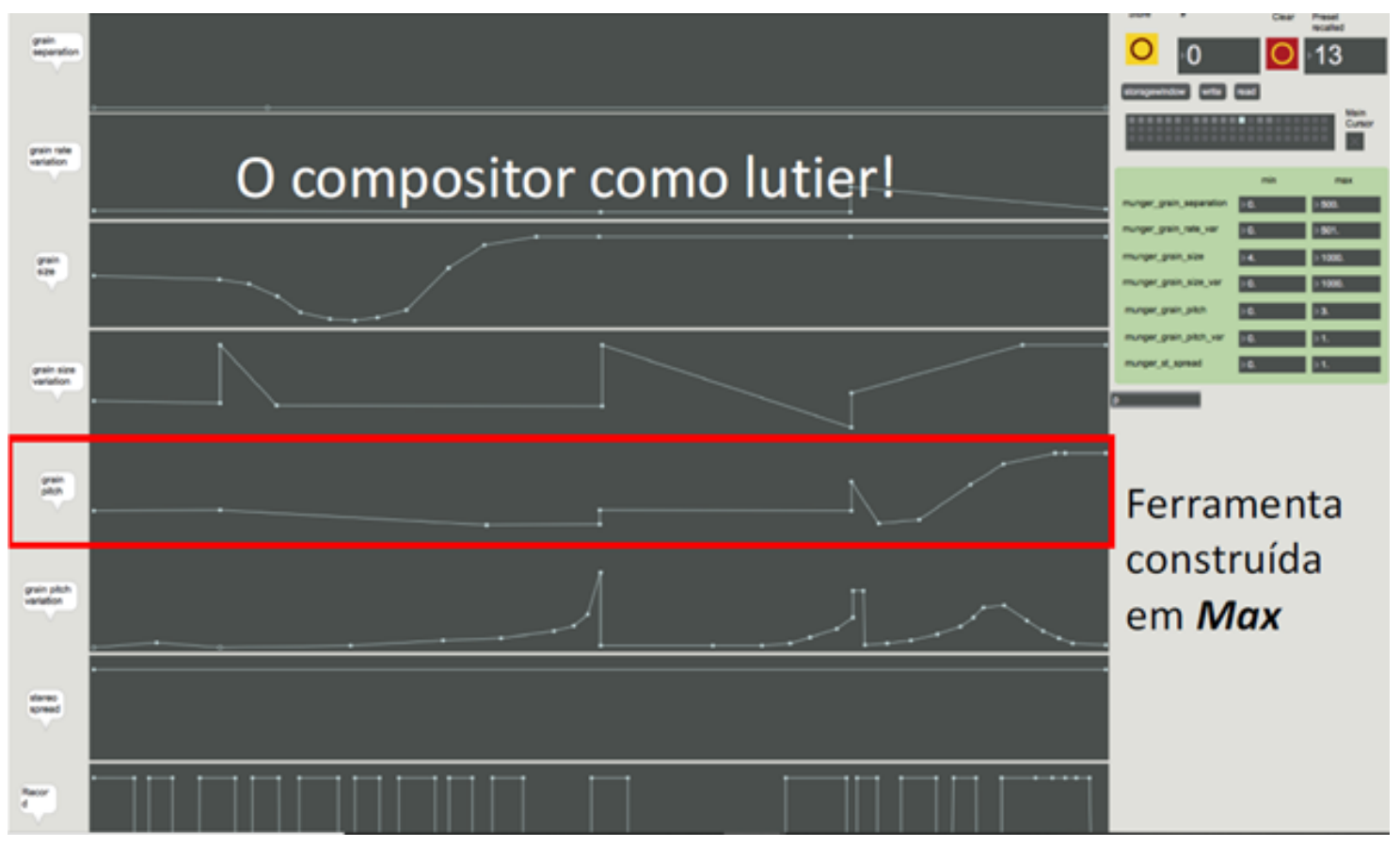

Fonte: $\operatorname{MALT}(2018$, p. 52)

Por outro lado, dentro do OpenMusic Malt também inscreveu as curvas de intensidade dramática para controlar parâmetros relativos à escrita da flauta (MALT, 2020b), embora não tenha nos deixado claro quais. As curvas de intensidade poderiam, por exemplo, ser representadas através do objeto BPF dentro do programa.

Sobre a relação das durações das seções com o andaime, Malt disse, em troca de e-mails, que não há relação direta entre as seções do texto na gravação com as seções nomeadas a partir do texto na peça, mas que as proporçôes estabelecidas como forma a partir do modelo literário o ajudaram a manter uma estrutura global, de modo que há um ponto culminante em torno da metade da peça (em torno dos 4 minutos) e um segundo ponto culminante no final da peça, na transição entre $L a$ Colline au Salmali de Fer e Enfers Éphémères (MALT, 2020). 


\subsection{Construção da eletrônica}

O andaime serviu como um suporte para a bricolagem de todos os elementos da eletrônica: estruturou a forma da peça, originou algumas das texturas que estão presentes na parte da eletrônica, forneceu a harmonia e estabeleceu um contorno para a colocação de outros elementos da eletrônica. Contudo, foi em sua maior parte retirado da versão final da eletrônica. Restaram os outros sons.

Estes sons foram criados a partir de várias amostras sonoras criadas e manipuladas pelo compositor através de diversas ferramentas. Algumas amostras possuem fonte reconhecível à escuta (por exemplo os sons de chave de flauta ou de espadas se chocando em combate que aparecem ao longo da peça) e foram obtidas a partir de gravações de áudio. Há também amostras de causas distintamente artificiais, criadas a partir de diversos tipos de síntese digital. Há ainda aqueles sons híbridos, criados a partir de gravaçôes de amostras e então manipulados até tornarem-se indistinguíveis das amostras iniciais (como, por exemplo, o próprio andaime).

Os sons também variam entre sons ruidosos e de altura definida, sons distintamente eletroacústicos e sons "concretos” (e, por vezes, de origem rastreável a algum instrumento musical). Alguns sons configuram também gestos rápidos, que se movimentam intensamente sobre outros sons, mais texturais e de evolução mais lenta.

Essa multiplicidade das amostras sonoras, que emergem a cada instante e dialogam intimamente com a escrita da flauta, confere à eletrônica um papel bastante presente, contrapondose à flauta quase como uma segunda voz (ou, talvez, como várias vozes). Khorwa-Myalwa não se trata de uma peça de música mista onde a eletrônica é apenas uma textura de fundo para um instrumento que realiza um solo, não é tampouco apenas uma expansão do timbre do instrumento. Os sons que compóem a eletrônica de Khorwa-Myalwa possuem vida própria, convergem e divergem dos gestos da flauta, dialogam com ela.

Para que a eletrônica fosse construída dessa forma, diversas amostras de som foram criadas, transformadas e processadas por aplicaçóes distintas - mais especificamente, nos ambientes de programação Max/MSP, Audiosculpt e OpenMusic. Tais amostras possuem múltiplas origens e relacionam-se de diversas maneiras com o modelo literário. 
Um dos elementos da eletrônica que possui origem mais clara são certos tipos de sons que soam como originários da própria flauta. Malt utilizou um banco de dados de sons de flauta baixo, incluindo diversos sons de técnicas estendidas. Esses sons foram de particular importância para criar o efeito amplamente explorado nesta peça de continuidade entre o que é executado pela flauta com o que aparece na eletrônica, como se os sons da eletrônica partissem da própria flauta (prática mais comum na música mista em tempo real).

Esse efeito possuí também um significado para a poética da peça e se associa ao modelo literário: o karma, de acordo com o Longchen Nyingtik Ngöndro, significa que "os resultados de Karmas não-virtuosos e virtuosos me perseguirão" (LING-PA, 1982, p. 6, tradução nossa ${ }^{3}$ ). Para Malt, este karma foi representado em Khorwa-Myalwa através da recorrência e aparição constante dos sons da flauta (2018, p. 68). Em especial os sons de chave que surgem na segunda subseção, Introduction (Karma) - 2, parecem perseguir o intérprete ao longo da peça. Eles surgem de modo sincronizado com a execução de dois golpes em pizzicato por parte da flauta baixo, fazendo parecer que há uma expansão do gesto da flauta para a eletrônica (Figura 4).

FIGURA 4 - Expansão do gesto da flauta na eletrônica. A recorrência dos sons de chave da flauta faz alusão ao karma. (Marcação em vermelho dos autores)

\section{Introduction (Karma) - 2}

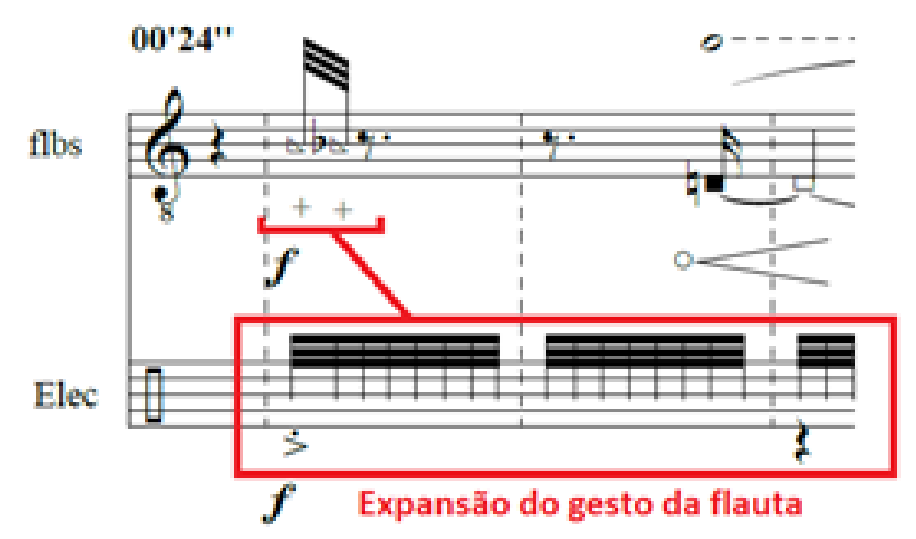

Fonte: MALT (2016, p. 1)

\footnotetext{
3 "The result of non-virtue and virtuous Karmas will follow after me" (LING-PA, 1982, p. 6).
} 
Outro exemplo desta maneira de construir e conceber a eletrônica em tempo diferido pode ser verificado nesta mesma subseção, com uma "falsa reverberação" de um golpe em pizzicato da flauta pela eletrônica (Figura 5). O uso do adjetivo "falsa" aqui quer dizer apenas que a reverberação não foi produzida em tempo real a partir do som da flauta em performance, embora o som tenha sido produzido por um dispositivo de reverberação a partir de amostras sonoras de flauta baixo.

FIGURA 5 - Falsa reverberação na eletrônica, sincronizada com o ataque da flauta. (Marcação em vermelho dos autores)

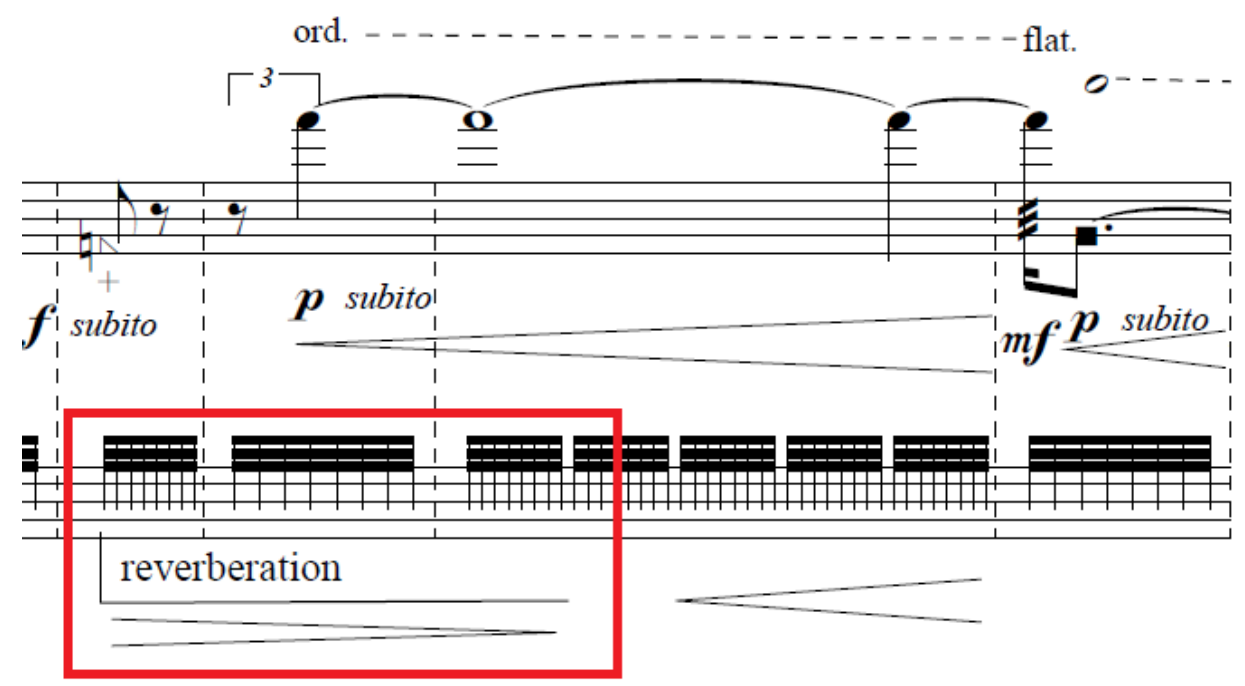

"Falsa reverberação"

Fonte: MALT (2016, p. 2)

Outro gesto da eletrônica que possui recorrência e regularidade ao longo da peça é o som de sinos. Estes sons marcam a entrada de cinco seções da peça: 1) a entrada da introdução, efetivamente iniciando a peça por meio deste gesto, 2) a entrada da seção Enfers Chauds, 3) a entrada de Enfers Froids, 4) a entrada dos Enfers Avoisinants, e 5) a entrada dos Enfers Éphémères.

Há ainda sons que parecem aludir diretamente ao texto: com a entrada da primeira subseção de Enfers Chauds, Resurrections, surgem gestos na eletrônica que se assemelham ao som de espadas se chocando - são chamadas por Malt na partitura de swords and blades (Figura 6), ou na tradução literal, espadas e lâminas. Estes sons provavelmente estão associados ao segundo verso do trecho "O sofrimento de Samsara" que faz referência a um dos Infernos Quentes (Enfers chauds, em francês): 
"Em um chão de ferro quente, meu corpo e cabeça serão cortados por instrumentos" (LING-PA, 1982, p. 6 - tradução nossa $\left.{ }^{4}\right)$.

Com o surgimento da subseção Réunion et Éclatement há na eletrônica o ataque de um som percussivo e seco, que está indicado na partitura como bammers (martelos) (Figura 6). Aqui, a origem desse som não é claramente discernível (de fato, o som parece com metais se chocando, mas não fica claro que sejam martelos), contudo o nome dado pelo compositor na partitura não faz restar dúvidas de que se trata de uma referência ao verso seguinte do texto: "Dividido por serras e esmagado por martelos quentes” (LING-PA, 1982, p.6 - tradução nossa ${ }^{5}$ ).

Na subseção Brûlant, cuja tradução literal é queimando, há também dois sons da eletrônica que foram nomeados por Malt como fire e high fire (Figura 6), ou, fogo e fogo alto em português. São também alusóes ao sexto verso d’O Sofrimento de Samsara: "Queimarei em um fogo de calor intenso - os Oito (Infernos Quentes)”(LING-PA, 1982, p. 6 - tradução nossa ${ }^{6}$ ).

FIGURA 6 - Em vermelho, sons que fazem referência a trechos do Longchen Nyingtik Ngöndro. (Marcação em vermelho dos autores)

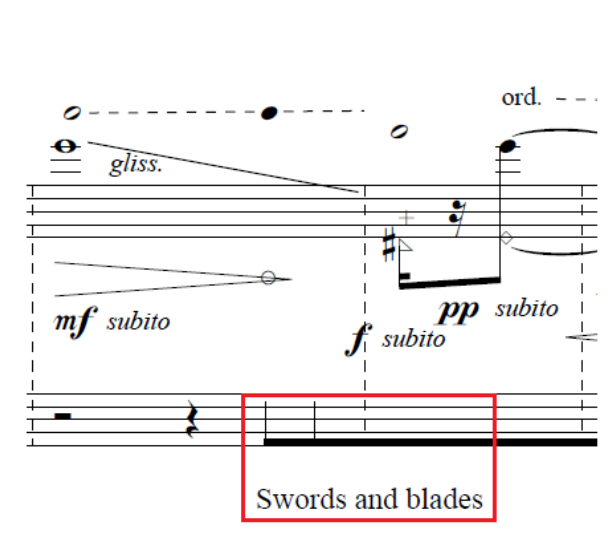

\section{Réunion et Eclatement}

$011^{\prime \prime}$
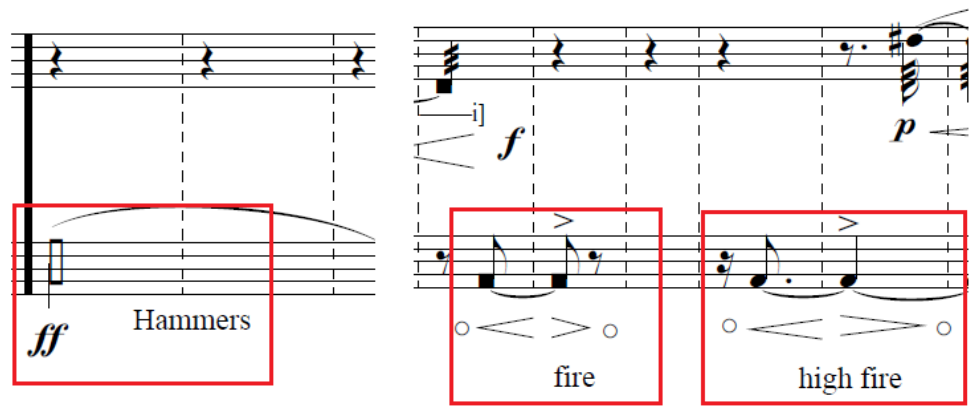

Fonte: Os autores a partir de MALT (2016, p. 2,3,5)

Estes e outros sons foram criados por Malt a partir do processamento e manipulação de amostras sonoras, bem como a partir da síntese digital. Como matéria prima, Malt fez uso de gravações pessoais feitas em uma viagem à Ilha de Sark (MALT, 2018, p. 39); gravações pessoais

\footnotetext{
4 "On a ground of burning iron my body and head will be cut by instruments," (LING-PA, 1982, p. 6).

5 "Split by saws and crushed by burning hammers" (LING-PA, 1982, p. 6).

6 "I will burn in extremely hot fire-the eight (hot hells)" (LING-PA, 1982, p. 6).
} 
feitas a partir do riscar de um lápis num papel (Ibid., p. 40); banco de amostras de sons de instrumentos como flauta, sinos, tigelas chinesas, tam-tams; bancos de amostras de sons concretos como sons de espadas, martelos, facas e fogo (Ibid., p. 42). Esses sons foram processados e transformados pelo compositor em diversos programas, plug-ins e linguagens.

Em uma versão do Factorsynth ${ }^{7}$ que roda em linha de comando, Malt realizou síntese cruzada entre diferentes amostras sonoras, criando sons híbridos (MALT, 2018, p. 55; MALT, 2020b). Também, como dito anteriormente, modelou sons em OpenMusic a partir dos modelos de JeanClaude Risset e os sintetizou utilizando uma biblioteca que possibilita a integração entre OpenMusic e Csound (Ibid., p. 54). Ainda no OpenMusic, utilizou a biblioteca OM-SuperVP para criar texturas com freezes aleatórios ${ }^{8}$ e dilataçóes espectrais, bem como alterou a altura de certos sons, corrigindo afinaçóes (MALT, 2020b). Também realizou outras transformações de amostras sonoras em Max/MSP e em Audiosculpt (MALT, 2018, p. 43; MALT, 2020b), que possui a já citada biblioteca SuperVP como recurso nativo para dilatação espectral.

Através dessa rede de processos, Malt criou as estruturas fundamentais para a construção da eletrônica de Khorwa-Myalwa, criou um extenso catálogo de amostras sonoras. O grande volume de arquivos rendeu ao compositor um enorme trabalho de mixagem, com mais de 50 pistas de áudio (MALT, 2018, p. 56) no projeto do Logic Pro X, programa utilizado para a montagem final da eletrônica (MALT, 2020b). Por fim, o Max/MSP foi o programa utilizado para a performance ao vivo da peça (MALT, 2018, p. 88).

\subsection{A escrita da flauta}

A distância geográfica entre Malt, que mora em Paris, e a flautista Profa. Dra Cássia Carrascoza, que mora em São Paulo, exerceu um grande peso na escolha de compor a peça para eletrônica em tempo diferido. Sem a possibilidade de ensaios presenciais, Malt achou que o uso da eletrônica em tempo real necessitaria de um grande aprendizado por parte da intérprete e,

\footnotetext{
7 Um sintetizador digital que realiza síntese cruzada e decomposição de sons. Mais informações em

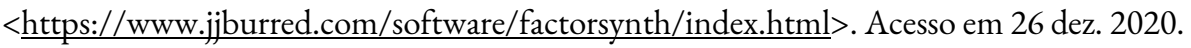

${ }^{8} \mathrm{O}$ efeito de freeze "pode ser obtido através do 'congelamento' de cada janela da TFCR (transformada de Fourier de curto termo)” (VICKERS et al., 2006, p. 3), repetindo o espectro sonoro captado no momento de acionamento do dispositivo.
} 
consequentemente, demandaria mais tempo, o que não era possível dada as condições de lançamento do CD Flauta Expandida, para o qual a peça foi composta. Tudo isto o levou a escolher o uso da eletrônica em tempo diferido para a peça (MALT, 2018, p. 9-10).

Como consequência deste processo, Malt criou a maior parte da eletrônica anteriormente à parte da flauta (Ibid., p. 73), de modo que a eletrônica conferiu à parte da flauta baixo sua moldura e contorno (MALT, 2018, p. 73-79; MALT, 2020b). Contudo, Malt faz uma ressalva: apesar da escrita propriamente dita ter sido posterior à criação da eletrônica, ele afirma que já possuía em mente diversas ideias para a parte da flauta ao compor a eletrônica, assim como a escrita da flauta também motivou recursivamente algumas mudanças na parte da eletrônica (MALT, 2020b).

Dito isto, a escrita da flauta possui dois eixos principais, que nortearam e guiaram as decisóes durante a escrita: o uso de técnicas estendidas e a amplificação da flauta (MALT, 2018, p. 11 e 58). É justo dizer que estes eixos também, de alguma forma, influenciaram a própria criação da eletrônica, já que para sua criação foram utilizadas diversas amostras sonoras de técnicas estendidas.

O uso de técnicas estendidas expandiu a paleta sonora da flauta, possibilitando ao longo da peça o surgimento de gestos ruidosos, sons percussivos, texturas rugosas, variações timbrísticas, etc. Estes sons puderam mesclar-se facilmente aos sons ruidosos e de origem misteriosa da parte da eletrônica, conferindo à Khorwa-Myalwa um mundo sonoro particular coeso e consistente. Foram utilizados quartos de tom, sons eólios (inspirados ou expirados, com ou sem mudança de posição da embocadura), ataques em pizzicato, tongue-rams, sons percussivos de chave, jet whistle, frullato, growl, harmônicos, glissando e glissando de harmônico.

Por outro lado, alguns desses sons só poderiam ser ouvidos em meio às texturas e gestos da eletrônica por meio de um sistema de amplificação bem elaborado. Foram usados nas gravações e performances três microfones, posicionados em lugares diferentes da flauta. Durante a performance, esses microfones são mixados ao vivo para melhor captar as ressonâncias do tubo e os sons ruidosos (Figura 7). 
FIGURA 7 - Trecho presente na bula da partitura a respeito dos detalhes técnicos de microfonação.

\section{Basic Flute amplification for Khorwa, Myalwa}

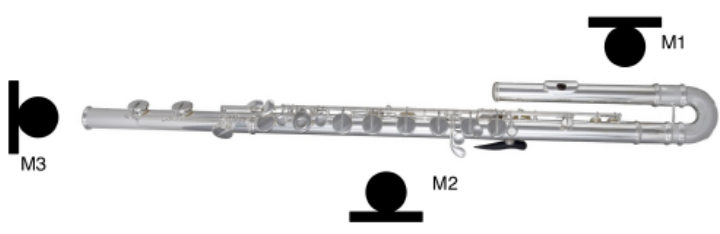

M1, cardio, like DPA4099 attached on the mouth piece

M2, Omni, like Neumann MK 184

M3, cardio, like DPA4099, attached on the foot piece and turned to inside (in order to retrieve the noisy sound and the tube resonances)

The three microphones must be mixed in real time in order to capture the noisy sounds and the tube resonances

Fonte: MALT (2016, p. 3)

A eletrônica também forneceu à flauta seu material harmônico (MALT, 2018, p. 74-79). Uma análise do espectro sonoro do andaime foi realizada em Audiosculpt, exportada em arquivo SDIF, interpretada em termos de alturas musicais pelo OpenMusic e representadas graficamente pelo Finale (MALT, 2020b). Este procedimento, contudo, não resultou em uma transcrição literal do andaime na parte da flauta; na maior parte da música este procedimento serviu para fundamentar as escolhas de Malt na escrita, como uma espécie de cantus firmus sobre a qual a linha da flauta pôde ser escrita (MALT, 2018, p. 74).

Podemos verificar na Figura 8 um dos rascunhos de Malt que contém este cantus firmus. Acima, podemos ver a impressão da transcrição do andaime realizada pelo compositor na primeira pauta, acompanhada de uma régua de segundos abaixo para demarcar o tempo. Mais abaixo há três outras pautas que foram impressas vazias, para que o compositor pudesse rascunhar sobre o papel à mão. Nelas estão esboçados trechos da subseção Extrêment [sic] Brûlant. 
FIGURA 8 - Rascunhos relativos à subseção Extrêment [sic] Brûlant (as marcações e textos em vermelho e em azul foram adicionados por nós e, portanto, não se encontram no original)

\section{"Cantus firmus" para a flauta, transcrito da eletrônica.}
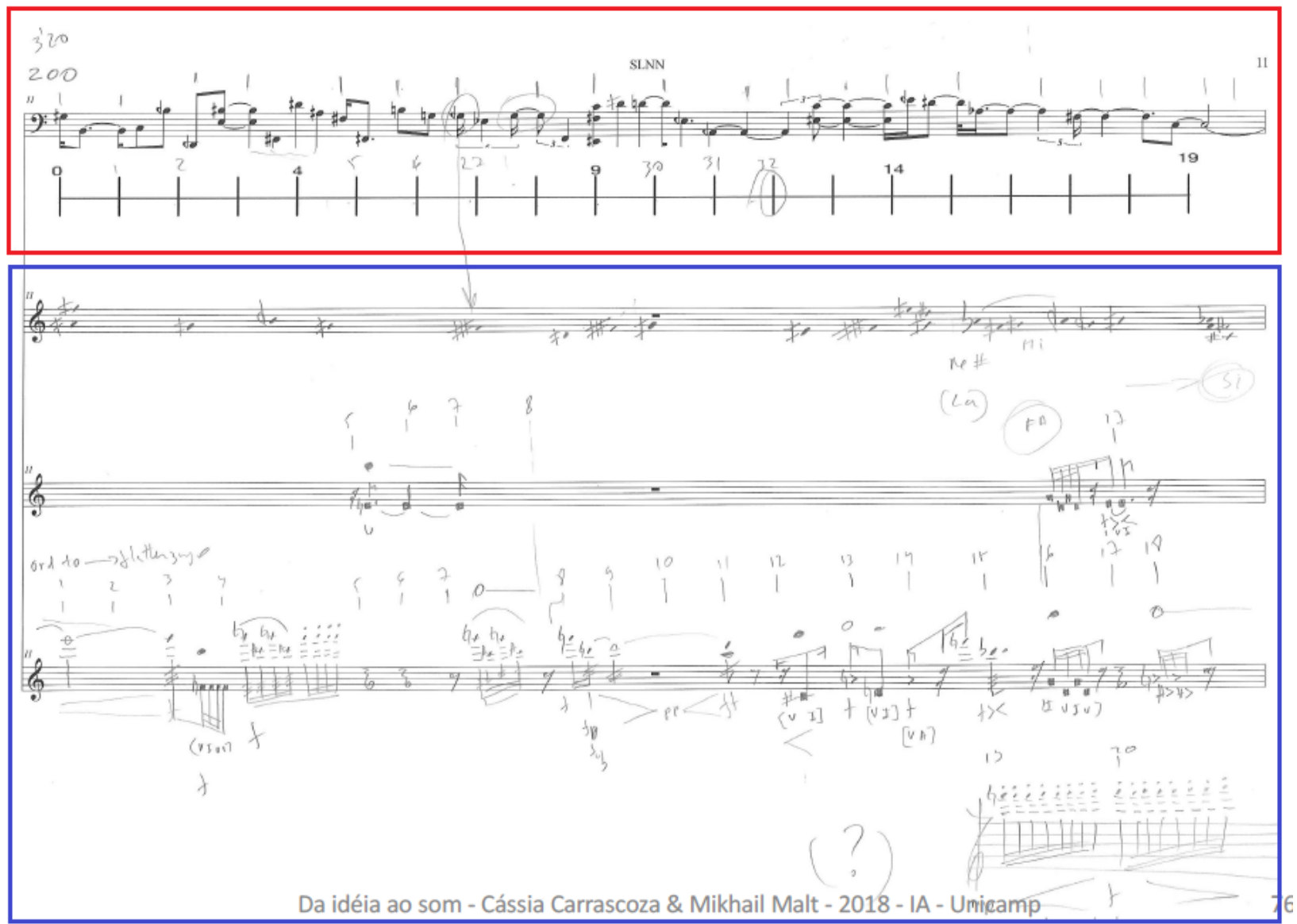

Rascunhos para a linha da flauta baixo.

Fonte: MALT (2018, p. 76)

A escolha dos ritmos, gestos, técnicas estendidas e dinâmicas foram, neste trecho, escritas e concebidas em papel, sem o auxílio direto do computador. Contudo, vale lembrar que a escrita da flauta também obedeceu às curvas de intensidade dramática desenhadas pelo compositor como modelo conceitual.

Diferentemente, na seção La colline au Salmali der Fer Malt optou por utilizar a ferramenta de quantização do OpenMusic para transcrever não apenas as notas da harmonia da eletrônica, mas também o ritmo. A partir deste material inicial, o compositor agiu livremente, omitindo notas e alterando duraçôes. O resultado deste processo foi exportado para o Finale, onde acentos foram adicionados na melodia, assim como as indicações para que o trecho seja tocado com som eólio e para que a flauta realize um crescendo junto com a eletrônica (Figura 9). 
FIGURA 9 - Processo de escrita da parte da flauta em La colline au Salmali de Fer.

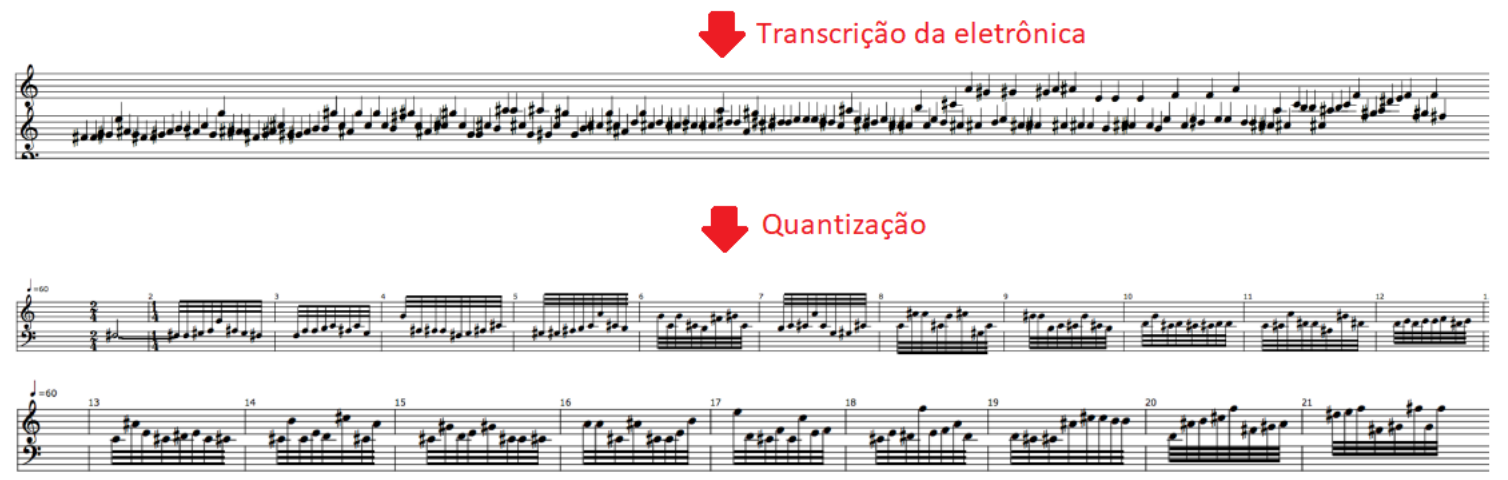

Omissão de notas, alteração de durações.

Adição de técnicas extendidas, acentos e dinâmicas.
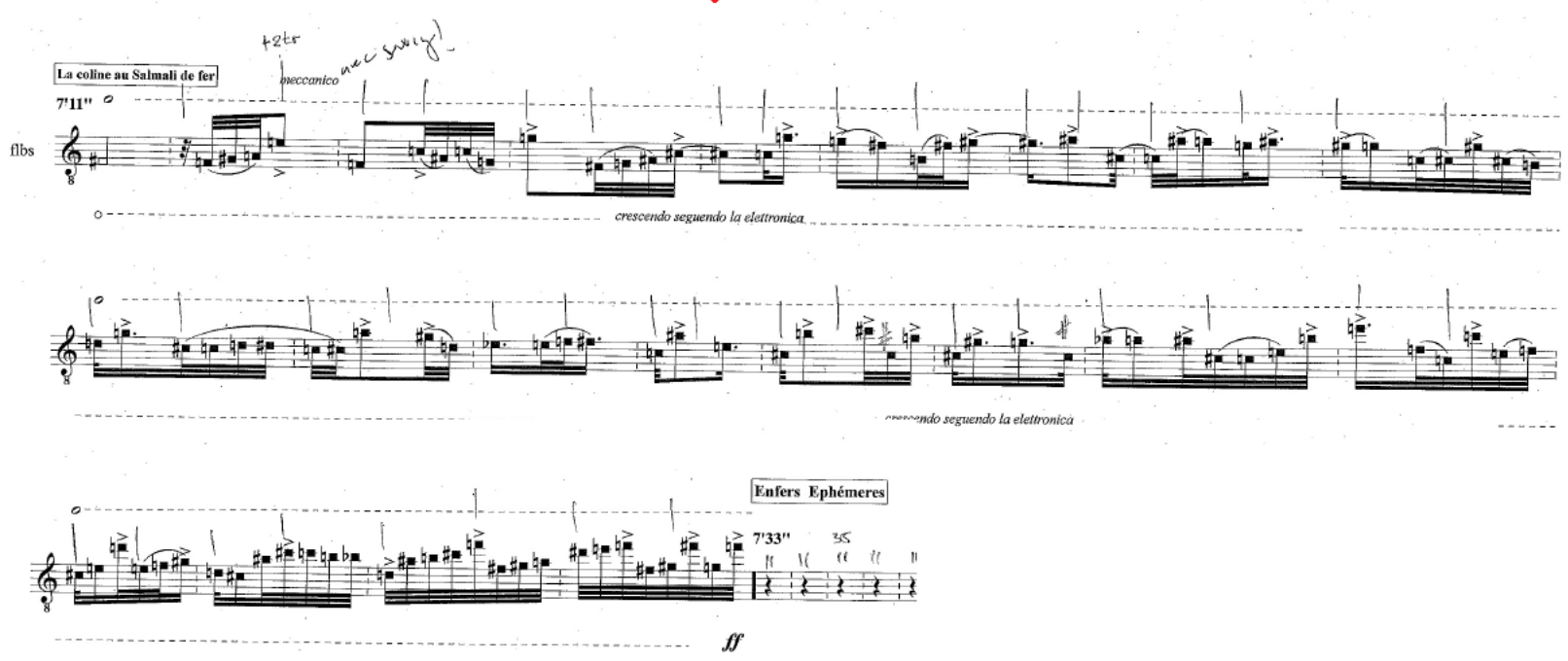

Fonte: Os autores.

As duas últimas seções da peça, Enfers Éphémères e Chant (triste) de renoncement/Coda, também possuem na parte da flauta uma melodia que teve como origem a transcrição do andaime. Aqui, contudo, a transcrição das parciais presentes no trecho correspondente do andaime serviu como um inventário de notas disponíveis para serem usadas para compor a melodia final.

Há ainda um outro elemento extrínseco ao som que aparece no processo de escrita da flauta. Para a melodia das três primeiras subseções da seção Enfers Avoisinants Malt realizou variações sobre a melodia da flauta presente nos quatro primeiros compassos do segundo movimento do Quarteto para flautas e cordas em Ré maior, K. 285, de Mozart (MALT, 2018, p. 70). Ele usou o contorno melódico e o registro instrumental como base, alterando livremente as relaçôes 
intervalares, ritmos, durações e dinâmica; adicionou também novas notas e técnicas estendidas (Figura 10).

FIGURA 10 - Comparação entre melodia do segundo movimento do quarteto para flauta e cordas de Mozart, K.285, e melodias das três primeiras subseções da seção Enfers Avoisinants.
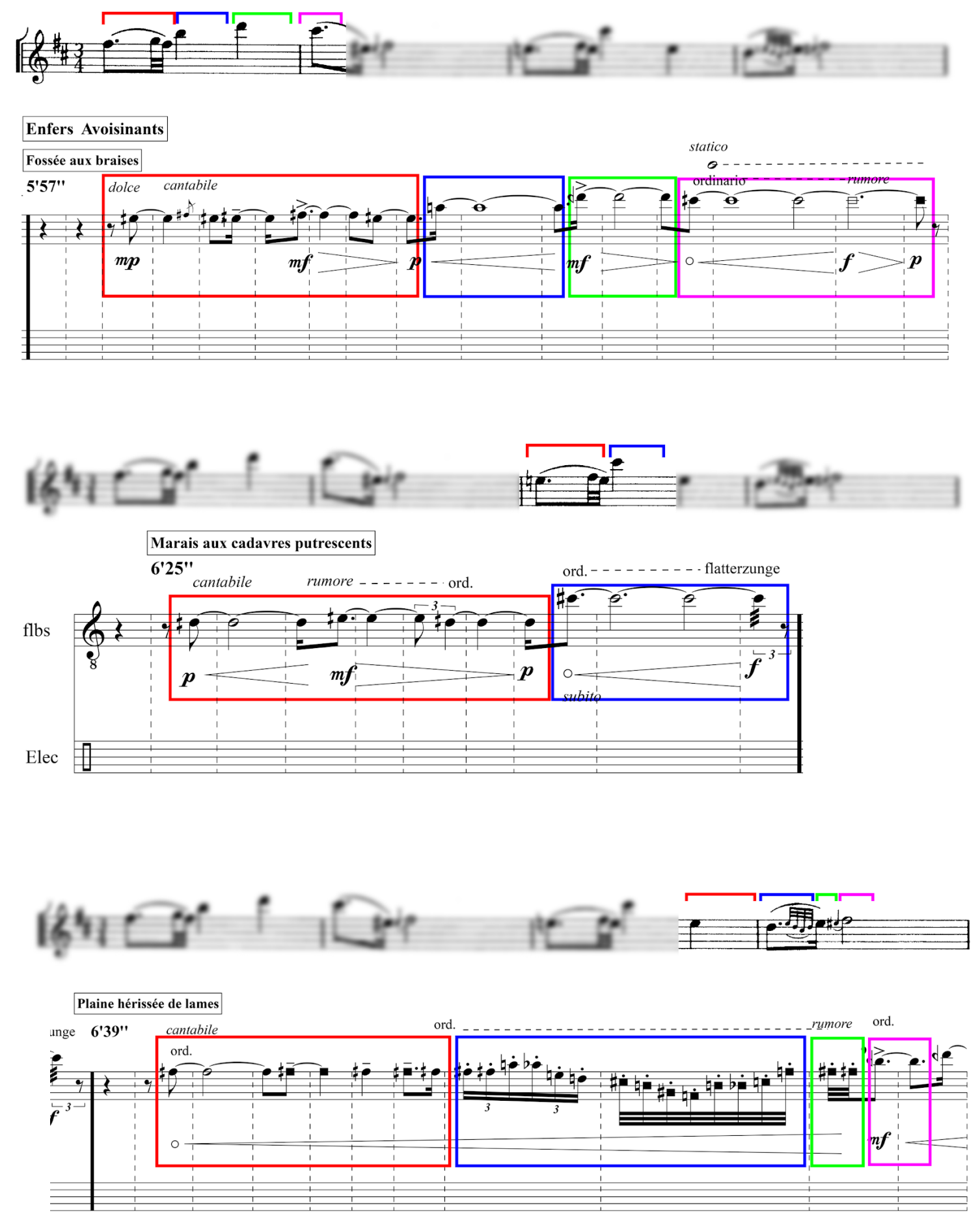

Fonte: Os autores. 


\subsection{Uma Hiperpartitura para o processo criativo de Khorwa-Myalwa}

Ao observarmos como Malt escreveu a parte da flauta, pudemos constatar que não houve um modelo computacional único para a criação da partitura, como por vezes ocorre na CAC. Entretanto, a parte da flauta foi escrita a partir de um andaime eletroacústico que serviu como cantus firmus e a partir dos elementos sonoros presentes na eletrônica. Esta última foi criada a partir de um modelo literário não-formal (que guiou decisões de cunho estético) e parece, por vezes, ela mesma representar as imagens descritas no texto.

O modelo literário foi o ponto de partida para todo o processo criativo. A partir dele surgiu a forma, que resultou na criação de curvas de intensidade dramática. Estas curvas serviram para o compositor representar a evolução dos parâmetros musicais, primeiramente, em modelos nãoformais (os rascunhos feitos em papel) e, posteriormente, em modelos formais (dentro do Max/MSP e do OpenMusic).

O andaime surgiu como uma síntese entre as referências extrínsecas ao som (o texto do Longchen Nyingtik Ngöndro) e as intrínsecas (a gravação da leitura do texto, a forma musical, a evolução dos parâmetros da granulação, etc.); ele foi criado a partir de uma amostra sonora processada pelo Audiosculpt (que fez uso da biblioteca nativa SuperVP) e granulado dentro do $\operatorname{Max} / M S P$.

A eletrônica, por sua vez, foi mixada dentro do Logic Pro X, através da bricolagem de inúmeras amostras sonoras processadas e construídas previamente. Estas amostras possuem origens diversas e foram escolhidas com base no modelo literário e na instrumentação da peça: bancos de gravações pessoais, amostras de sons instrumentais, amostras de sons concretos, bancos de amostras sonoras online. Elas foram também processadas e criadas por diversas ferramentas: o Factorsynth, o OpenMusic (com o uso do SuperVP e do Csound), o Audiosculpt e o Max/MSP.

A parte da flauta partiu em grande parte do andaime. Ele foi analisado pelo Audiosculpt, interpretado pelo OpenMusic de ao menos duas formas distintas e exportado para o Finale. Do Finale foram impressos rascunhos, e os rascunhos depois retornaram ao Finale para a criação da partitura final. Também fez parte da escrita da flauta a melodia do Quarteto K.285 de Mozart, que forneceu o perfil melódico para a criação da melodia da flauta. O OpenMusic também permitiu a 
inscrição de curvas dramáticas para a escrita da flauta, como nos informou Malt em troca de emails (MALT, 2020b).

Por fim, a peça é executada em performance e em ensaio através do Max/MSP.

Esses diversos programas, aplicações e ferramentas utilizadas durante o processo de composição se conectam numa rede de técnicas, modelos e significados a partir da representação digital encapsulada no computador, a hiperpartitura, que também pode ser vista como uma representação do agenciamento cognitivo do compositor. Escolhemos representar a hiperpartitura criada em Khorwa-Myalwa através do seguinte grafo, que nos forneceu conexôes entre os elementos utilizados na criação da obra para então discutir o processo criativo como um todo (Figura 11):

FIGURA 11 - Representação da hiperpartitura e do processo criativo por trás de Khorwa-Myalwa.

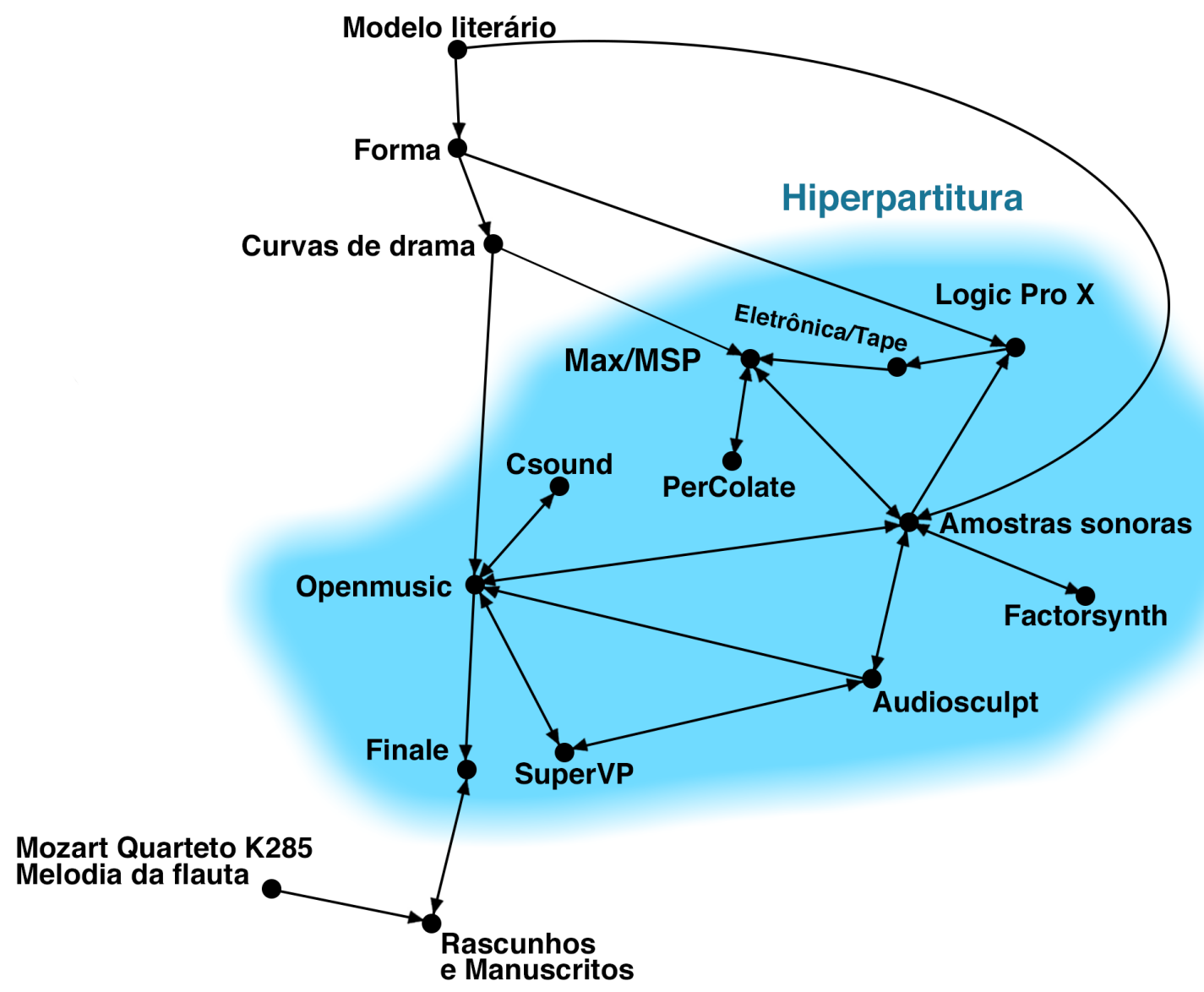

Fonte: Os autores 
Durante o processo criativo, o compositor criou esta rede da maneira mais natural e espontânea, deu preferência a programas e procedimentos a que estava mais familiarizado em seu atelier composicional, sem especificar de antemão os nós e conexões da rede. O resultado deste processo, então, foi interpretado por nós como a hiperpartitura que apresentamos na Figura 11.

Portanto, não nos surpreende que o OpenMusic seja um dos bubs do nosso grafo: como Malt foi um dos responsáveis pela criação de ao menos duas bibliotecas (Combine e Filters ${ }^{9}$ ) e materiais pedagógicos (MALT, 2017) para a linguagem, é esperado que tenha utilizado o OpenMusic de diversas maneiras e para diversos fins.

Outro bub que surge em nossa hiperpartitura é o banco de amostras sonoras, já que tais amostras compóem os gestos e as texturas eletroacústicas da peça. Portanto, tiveram de ser cuidadosamente escolhidas e modificadas, pois se ligavam diretamente à poética estabelecida através do texto e foram peças importantes para estruturar os momentos da música, dar coesão ao "mundo" sonoro e brincar com a percepção do ouvinte. As amostras foram importantes não somente para a construção dos gestos e texturas da eletrônica, mas também para criar o andaime e, consequentemente, estruturar a forma da peça (a amostra de som da leitura do texto, o arquivo de saída do Audiosculpt e, por fim, o próprio andaime que é ele mesmo uma amostra sonora).

Um terceiro e último bub do processo criativo é o Max/MSP - ambiente de programação para o qual Malt também criou bibliotecas. Este foi utilizado para criar o andaime com o uso do objeto munger , presente na biblioteca PerColate, para criar e processar outras amostras de $\operatorname{som}^{10}$ e, finalmente, para os ensaios por meio de um patch criado com esta finalidade e para a performance ao vivo, que fez uso de outro patch distinto.

Ainda, a representação em papel milimetrado escolhida por Malt para modelar a evolução da peça - as curvas de intensidade dramática -, são também representaçôes facilmente transponíveis para os programas usualmente associados à CAC, tendo sido utilizadas diretamente em ao menos dois (Max/MSP e OpenMusic). A escolha de usar o papel milimetrado também indica uma familiaridade com as representações calculáveis, sejam discretas (como é o caso das proporçóes de cada seção da forma desenhadas sobre o papel) ou contínuas (como é o caso das curvas). São

\footnotetext{
${ }^{9}$ Bibliotecas do OpenMusic: <https://openmusic-project.github.io/libraries.html $>$. Acesso em 28 dez. 2020.

${ }^{10}$ É possível que haja outras bibliotecas utilizadas dentro do Max/MSP para o processamento das amostras, contudo, nada nos foi informado.
} 
escolhas condicionadas pela enorme familiaridade do compositor com o computador e suas representaçôes.

Outras curvas também foram criadas dentro do Logic Pro X para automatizar a mixagem; estas não foram concebidas previamente em papel pelo compositor, embora ainda possuam relação global com a forma da peça (MALT, 2020b). A forma, por conseguinte, é invariavelmente inscrita dentro do programa pelo próprio processo de composição da eletrônica.

Notemos também que o processo de composição não foi organizado de maneira sequencial, mas sim organizado tal como uma rede de interações e processos. Ele não começou com a escrita da armadura de clave e terminou com a barra dupla final. Do contrário, há inúmeros processos recursivos, idas e vindas entre aplicações diversas (que se conectam de maneiras diferentes), entre papel e computador, entre a simulação (e escuta) em tempo real da eletrônica e as simulaçóes mentais do compositor.

\section{Discussão e apontamentos finais}

Observamos ao longo do texto como que o computador e a escrita atuam como agentes do processo cognitivo humano, verdadeiras tecnologias intelectuais. Vimos também que estas diferentes tecnologias nos imputam diferentes maneiras de compreender, representar e pensar a realidade - inclusive o tempo. A escrita nos entregou sua linearidade narrativa, criou o tempo histórico, suspendeu o pensamento no tempo e criou formas de conhecimento isoladas dos contextos em que foram concebidas (as teorias). Já com o computador, surgem os hipertextos, os modelos computacionais e, consequentemente, as simulaçóes - surge o conhecimento por simulação.

A partir da noção de hipertexto propomos compreender a composição assistida por computador como a criação de uma rede hipertextual, a qual chamamos de hiperpartitura, que possui como fim auxiliar o compositor em seu processo criativo. Essa rede, além de possibilitar e facilitar novos processos de síntese sonora, também fornece valiosas representações para pensar música. Por se tratar de uma rede, nos pareceu natural representar a hiperpartitura através de um 
grafo, de modo que os nós são as ferramentas e técnicas utilizadas e as arestas são as associações tecidas pelo compositor.

A representação da hiperpartitura, contudo, não pretende ser total. É uma maneira de visualizar a análise através de um recurso gráfico, é a criação também de um modelo para pensar o processo criativo e, como qualquer modelo, é criado a partir de escolhas guiadas por finalidades.

Não obstante, se apresentou como um recurso valioso para a escrita deste texto: na tentativa de criar o grafo da hiperpartitura de Khorwa-Myalwa, foi necessário compreender melhor como as ferramentas computacionais utilizadas comunicavam-se entre si, como os modelos mentais foram passados de um espaço conceitual mental para um espaço informático, como essas representaçóes estruturam o processo criativo como um todo, etc. Foi uma interessante ferramenta de análise. Também nos beneficiamos especialmente do contato direto com Mikhail Malt, essencial para descobrir as minúcias do processo composicional: pudemos tirar dúvidas, ter acesso aos rascunhos, ter acesso ao arquivo do andaime e à eletrônica em tempo diferido.

Pensar a hiperpartitura é, portanto, uma valiosa ferramenta para a análise do processo criativo. Através dela é possível compreender mais amplamente as ferramentas utilizadas e, principalmente, seus agenciamentos e associaçóes (incluindo os agenciamentos cognitivos), iluminando os caminhos do processo composicional. Ao olharmos para o processo criativo de Khorwa-Myalwa sob a ótica da criação de uma rede, pudemos compreender como se deu a prática do compositor, o seu fazer, a “mão na massa”.

Não apenas, mas pensar a hiperpartitura é ainda uma valiosa ferramenta para compositores interessados na CAC (em especial estudantes de composição), ao permitir uma maior compreensão da rede de ferramentas disponíveis e ao fornecer um tipo de representação não-linear para o processo criativo. 


\section{AGRADECIMENTOS}

Agradecemos ao Prof. Dr. Mikhail Malt pelo apoio, confiança e colaboração ativa. Os rascunhos, arquivos e entrevistas foram de extrema importância para nós, sem os quais essa pesquisa não teria sido possível. Agradecemos também à Profa. Dra. Cássia Carrascoza pelo apoio e por nos ceder uma cópia do CD tempo transversal flauta expandida.

Agradecemos ainda à Fundação de Amparo à Pesquisa do Estado de São Paulo - FAPESP pelo financiamento desta pesquisa, processo no 2019/20685-4, sob o título de Análise do processo criativo e da forma em Khorwa-Myalwa, para flauta baixo e eletrônica, de Mikbail Malt.

\section{REFERÊNCIAS}

ASSAYAG, Gérard; RUEDA, Camilo; LAURSON, Mikael; AGON, Carlos; DELERUE, Oliver. Computer-Assisted Composition at IRCAM: From PatchWork to OpenMusic. Computer Music Journal, v. 23, n. 3, p.59-72, 1999.

BARABÁSI, Albert-László. Network Science. Cambridge University Press, 2016.

BODEN, Margaret. The Creative Mind: Myths and Mechanisms. London: Routledge, 2004. Computer Models of Creativity. AI Magazine, v. 30, n.3, p.23-34, 2009.

BUSH, Vannevar. As we may think? Life Magazine, Chicago, vol. 19, n. 11, 10 de setembro de 1945.

BUXTON, William. A Composer's Introduction to Computer Music. Interface, vol. 6, n. 2, p.5772, 1977.

DONIN, Nicolas. Genectic Criticism and Cognitive Anthropology: A Reconstruction of Phillipe Leroux's Compositional Process for Voi(rex). Genetic Criticism and the Creative Process: Essays from Music, Literature and Theater. Woodbridge, p.193-215, 2009.

DRIEDGER, Jonathan; MÜLLER, Meinard. A Review of Time-Scale Modification of Music Signal. Applied Sciences. vol. 6, n. 2: 57, p. 1-26, 2016.

FÉRON, François-Xavier. The Emergence of Spectra in Gérard Grisey's Compositional Process: From Dérives (1973-74) to Les espaces acoustiques (1974-85), Contemporary Music Review, vol. 30, n. 5, p. 343-375, 2011.

GIERE, Ronald. How Models Are Used To Represent Reality. Philosophy of Science, vol. 71, p. 742-752, 2004.

HILLER, Lejaren; ISAACSON, Leonard. Experimental Music: composition with an electronic computer. New York: McGraw-Hill Book Company Inc., 1959. 
LASKE, Otto. Toward a Definition of Computer Music. In: INTERNATIONAL COMPUTER MUSIC CONFERENCE, 1981, Denton. Anais... Denton, p.31-56.

LING-PA, Jig-Me. The Dzogchen: Innermost Essence Preliminary Practice. 4. ed. Nova Delhi: Library of Tibetan Works and Archives, 2002.

LÉVY, Pierre. As tecnologias da inteligência. 2. ed. São Paulo: Editora 34, 2010.

KIMIZUKA, Yuri. Modelização e pensée sauvage na prática composicional. 2019. Tese de doutorado. Escola de comunicação e artes - Universidade de São Paulo, São Paulo.

MALT, Mikhail. La représentation dans le cadre de la composition et de la musicology assistées par ordinateur - De la raison graphique à la contrainte cognitive. 2015. Tese (Doutorado em Musicologia). École Doctorale des Humanités - Université de Strasbourg, Strasbourg. . Khorwa-Myalwa: Les Enfers. Les Lilas: independente, 2016. Partitura, 15 páginas, para flauta baixo e eletrônica em tempo diferido. . Pode-se aprender OpenMusic em três dias? Orfeu, v. 2, n. 1, p. 243-255, 2017. . Da ideia ao som. Conferência, Unicamp, 2018. . Trabalho de Pesquisa - análise de Khorwa-Myalwa - dúvidas [mensagem pessoal]. Mensagem recebida por <EMAIL DO AUTOR > em 09 jun. 2020a. . Últimas perguntas sobre Khorwa-Myalwa. Finalização da pesquisa de IC [mensagem pessoal]. Mensagem recebida por <EMAIL DO AUTOR>, em 18 dez. 2020b.

MANIATAKOS, Fivos; ASSAYAG, Gérard; BEVILACQUA, Frédéric; AGON, Carlos. On architecture and formalisms for computer assisted improvisation. In: Sound and Music Computing Conference, Barcelona, 2015.

MURAIL, Tristan. Spectra and Sprites. Contemporary Music Review, vol. 24, n.2-3, p. 137-147, 2005.

PUCKETTE, Miller. A case study in software for artists: Max/MSP and Pd. In: LARTIGAUD, David-Olivier (Org.), Ed., Art++, Editions Hyx, 2009, p.1-9.

SMITH, Leland. SCORE - A Musician's Approach to Computer Music. Journal of the Audio Engineering Society, vol. 20, n. 1, p.7-14, 1972.

VICKERS, Earl; WU, Jiang-Lung (Larry); KRISHNAN, Praveen Gobichettipalayam; SADANANDAM, Ravirala Narayana Karthik. Frequency Domain Artificial Reverberation using Spectral Magnitude Decay. In: Audio Engineering Society Convention, San Francisco, 2006.

XENAKIS, Iannis. Formalized Music. Stuyvesant, New York: Pendragon Press, 1992. 


\section{SOBRE OS AUTORES}

Lucas Quinamo é mestrando em música pela Unicamp. Desenvolve pesquisa na área de sonologia sob orientação do Prof. Dr. Danilo Rossetti e co-orientação do Prof. Dr. Jônatas Manzolli. Integra o coletivo de arte digital Ballet Fractal. Também é parte do coletivo Descompasso, com o qual mantém o canal Descompasso - Score Follower. Trabalha principalmente na área de música eletrônica e composição assistida por computador. Da sua produção musical fazem parte a música eletrônica de pista, a música eletroacústica, a música de câmara e a música mista. ORCID: https://orcid.org/0000-0002-1596-0026. E-mail: lucasquinamo@gmail.com

Danilo Rossetti é professor, pesquisador e compositor cujo trabalho enfoca o uso da tecnologia em processos criativos, performances e análises musicais. É professor do Departamento de Artes da UFMT e professor colaborador da PósGraduação em Música do Instituto de Artes da UNICAMP. Realizou pesquisa de pós-doutorado no Núcleo Interdisciplinar de Comunicação Sonora da UNICAMP, e é doutor em Música pela mesma instituição, com período sanduíche na Université Paris 8. Suas composiçôes foram tocadas em diversos eventos como ICMC, CMMR, NYCEMF, CICTem, NIME, NowNet Arts, BIMESP, SBCM, ANPPOM, File Hipersônica e Bienal de Música Contemporânea da FUNARTE. ORCID: https://orcid.org/0000-0001-7690-8048. E-mail: d.a.a.rossetti@gmail.com

Jônatas Manzolli combina a criação musical contemporânea e as ciências cognitivas com foco nos diálogos entre música e ciência. Esse estudo interdisciplinar resulta em obras eletroacústicas, instrumentais e multimodais. Compositor e matemático, professor titular do Instituto de Artes da Universidade Estadual de Campinas, Brasil, é um dos pioneiros na pesquisa brasileira em computação musical. Ele tem sido um pesquisador convidado no Instituto de Neuroinformática, Suíça, e no Grupo SPECS (SPECS) na Universitat Pompeu Fabra, Barcelona. Ele também é colaborador do CIRMMT, McGill University, Montreal, desde 2016. As realizações mais importantes de Jônatas Manzolli enfatizaram a delicada relação entre homem e máquina, incluindo o uso de inteligência artificial com interfaces digitais. ORCID: https://orcid.org/0000-0003-4257-7118. E-mail: jotamanzo@gmail.com 